\title{
Supporting Information for Control of Charge Carriers and Band Structure in 2D Monolayer Molybdenum Disulfide via Covalent Functionalization
}

\author{
Leighton O. Jones, Martín A. Mosquera, Mark A. Ratner, George C. Schatz*
}

Contact GCS* g-schatz@northwestern.edu

Department of Chemistry, Northwestern University, Evanston, IL, 60208, USA 


\section{Contents}

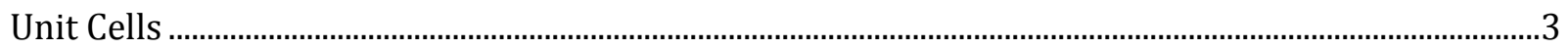

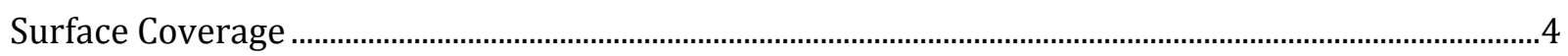

PDOS, $\mathrm{MoS}_{2}+\mathrm{F}$

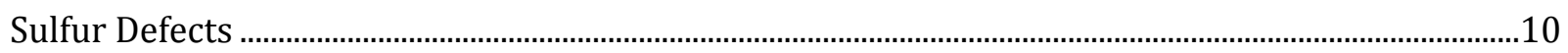

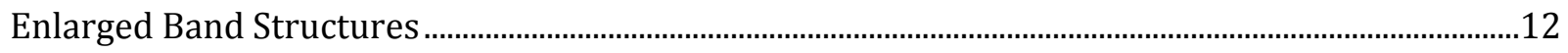




\section{Unit Cells}

The direct gap of a monolayer of $\mathrm{MoS}_{2}$ changes curvature and position in the Brillouin zone based on the unit cell size, not just the number of k-points or $\mathrm{k}$ path.

\begin{tabular}{|c|c|c|c|c|c|}
\hline Cell size & K point grid & Band Gap $(\mathrm{eV})$ & Gap position & Program & Method \\
\hline $1 \times 1$ & $\begin{array}{c}15 \times 15 \times 1^{1} \\
9 \times 9 \times 1^{2}\end{array}$ & $\begin{array}{c}1.62^{1} \\
*\end{array}$ & $\mathrm{~K} \rightarrow \mathrm{K}^{\prime 1}$ & VASP & PBE \\
\hline $2 \times 2$ & $\begin{array}{c}9 \times 9 \times 1^{3} \\
24 \times 24 \times 1^{4}\end{array}$ & $\begin{array}{l}\sim 1.9^{\dagger} \\
1.65^{4}\end{array}$ & $\mathrm{~K} \rightarrow \mathrm{K}^{3}$ & $\begin{array}{l}\text { SIESTA }^{3} \\
\text { VASP }^{4}\end{array}$ & $\begin{array}{l}\text { LDA }^{3} \\
\text { PW91 }^{4}\end{array}$ \\
\hline $3 \times 3$ & $\begin{array}{c}5 \times 5 \times 1^{5} \\
15 \times 15 \times 1^{1} \\
24 \times 24 \times 1^{3}\end{array}$ & $\begin{array}{l}1.69^{5} \\
1.62^{1} \\
\sim 1.9^{\dagger}\end{array}$ & $\Gamma \rightarrow \Gamma^{\prime 1,3,5}$ & VASP & PBE \\
\hline $4 \times 4$ & $\begin{array}{c}5 \times 5 \times 1^{6} \\
25 \times 25 \times 1^{7} \\
30 \times 30 \times 1^{8}\end{array}$ & $\begin{array}{c}1.67^{6} \\
1.90^{7} \\
1.58 / 1.87^{8}\end{array}$ & $\mathrm{~K} \rightarrow \mathrm{K}^{\prime 6-8}$ & $\begin{array}{c}\text { VASP }^{6} \\
\text { VASP }^{7} \\
\text { SIESTA }^{8}\end{array}$ & $\begin{array}{c}\text { PBE } \\
\text { PBE } \\
\text { LDA/PB } \\
\text { E }\end{array}$ \\
\hline $\begin{array}{l}5 \times 5 \\
\exp \end{array}$ & $\begin{array}{c}5 \times 5 \times 3^{9} \\
\text { NA }\end{array}$ & ${ }^{*} 1.69^{10}, 1.90^{11}$ & $\begin{array}{l}K \rightarrow K^{\prime 9} \\
K \rightarrow K^{\prime 11}\end{array}$ & $\begin{array}{l}\text { VASP }^{9} \\
\text { NA }\end{array}$ & $\begin{array}{l}\text { PBE } \\
\text { NA }\end{array}$ \\
\hline
\end{tabular}

An example of the different direct band gaps for different unit cell sizes is seen in Figure S1, which shows calculated band structures of pristine monolayer $\mathrm{MoS}_{2}$, with periodic DFT (non-spin polarized) using Siesta. We see, in agreement with the references in Table S1 above, that the direct band gap with a $3 \times 3$ unit cell occurs in a $\Gamma \rightarrow \Gamma^{\prime}$ transition, which is unique. In the manuscript, we deploy a $4 \times 4$ unit cell.
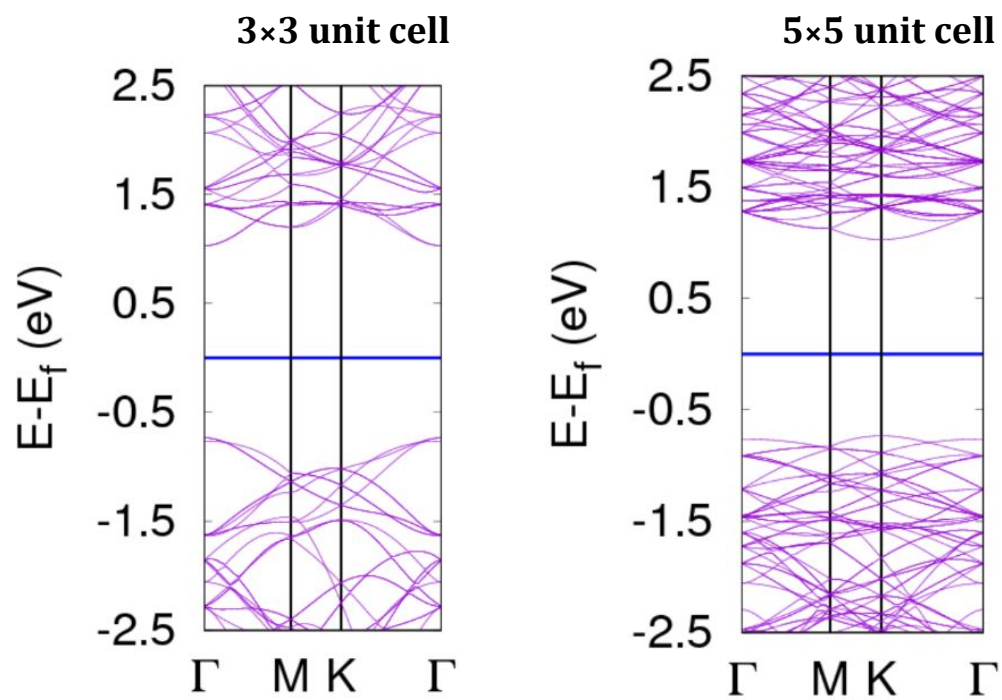

Figure S1. Band structure of pristine monolayer $\mathrm{MoS}_{2}$, for both $3 \times 3$ and $5 \times 5$ unit cells. 


\section{Surface Coverage}

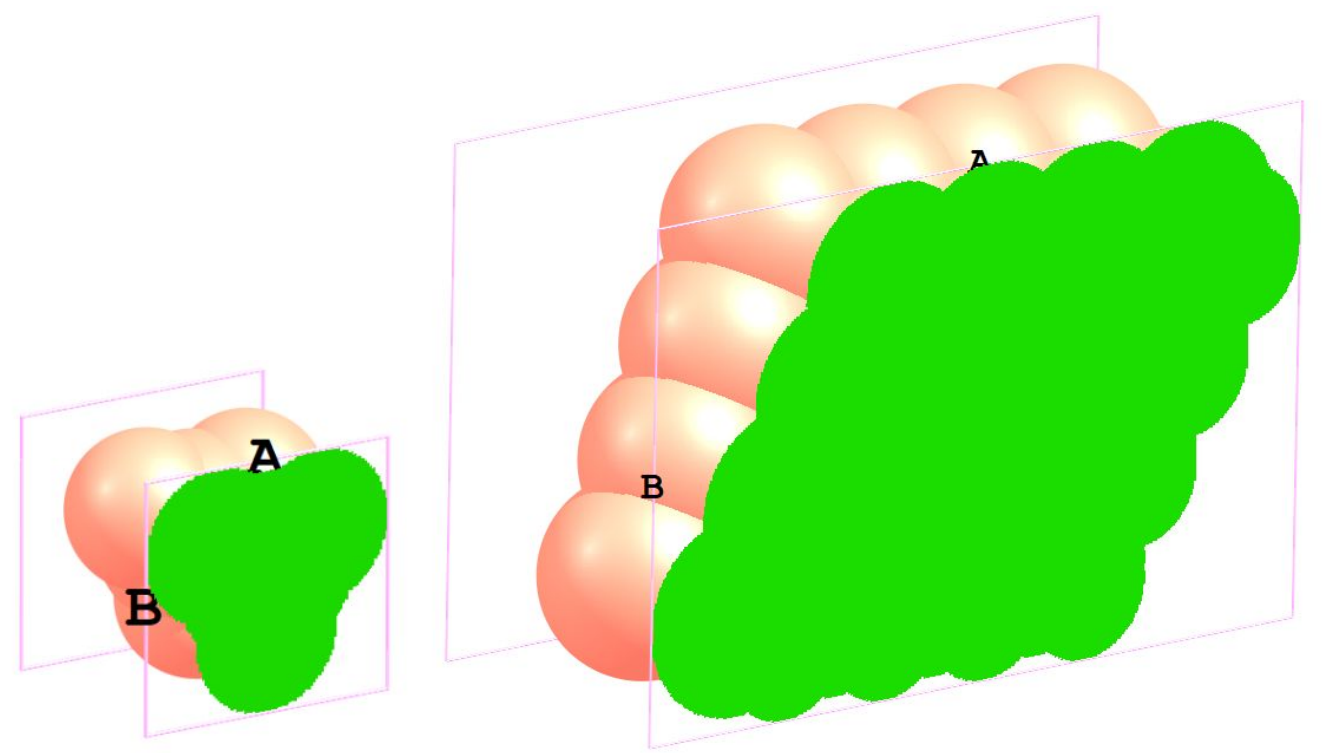

Figure S2. Surface area calculations of Me (left) and $1 \mathrm{H}-\mathrm{MoS}_{2} 4 \times 4$ unit cell (right), performed in ChemCraft (version 1.8). Area of $\mathrm{Me}=14.248 \AA^{2}$. Area of $\mathrm{MoS}_{2} 4 \times 4$ unit cell: $214.985 \AA^{2}$. Surface coverage $=6.63 \%$. A and $\mathrm{B}$ are labels provided by the Chemcraft program which gives the area of the box $A B$, not used here. 
PDOS, $\mathrm{MoS}_{2}+\mathrm{F}$

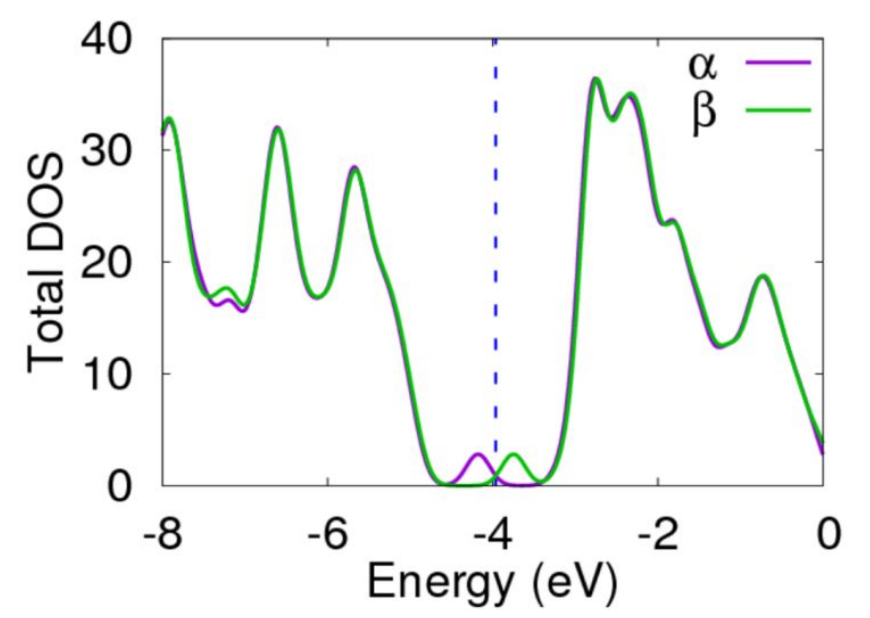

Figure S3. Total spin-polarized density of states (TDOS).

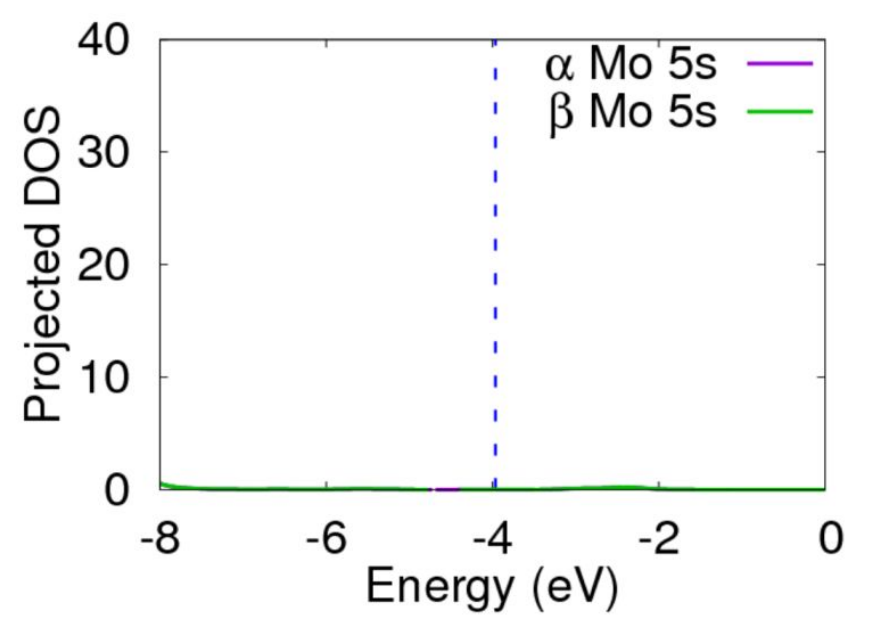

Figure S4. Projected spin-polarized density of states (PDOS) for the given orbital.

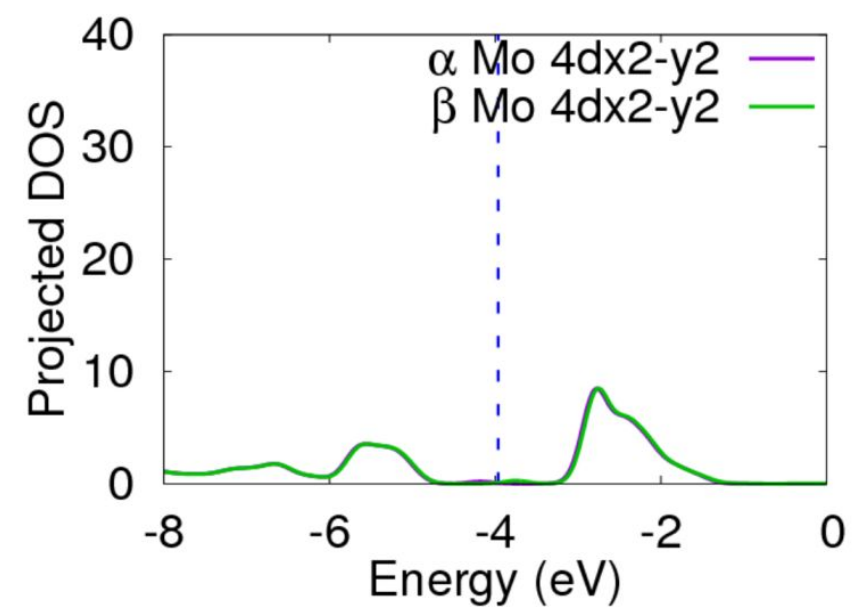

Figure S5. Projected spin-polarized density of states (PDOS) for the given orbital. 


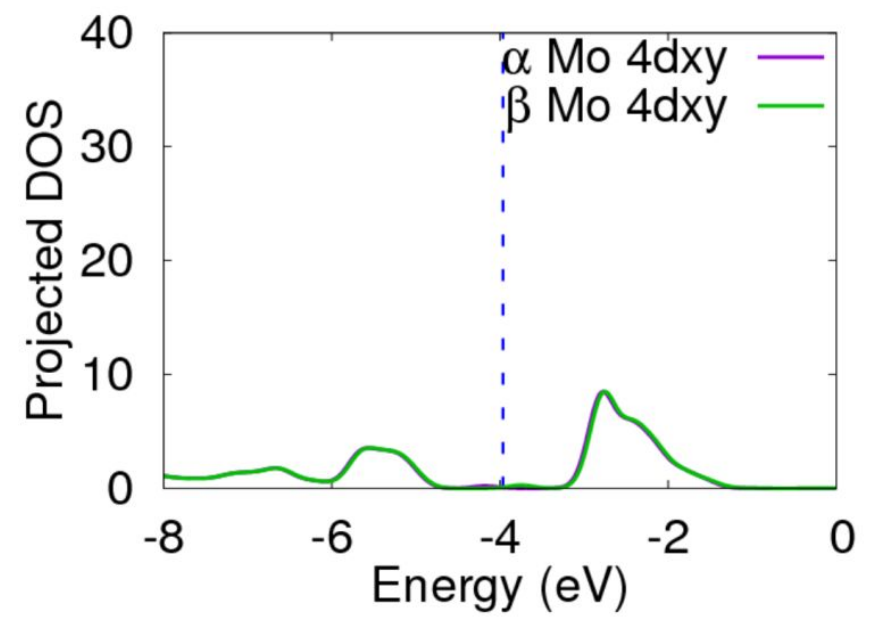

Figure S6. Projected spin-polarized density of states (PDOS) for the given orbital.

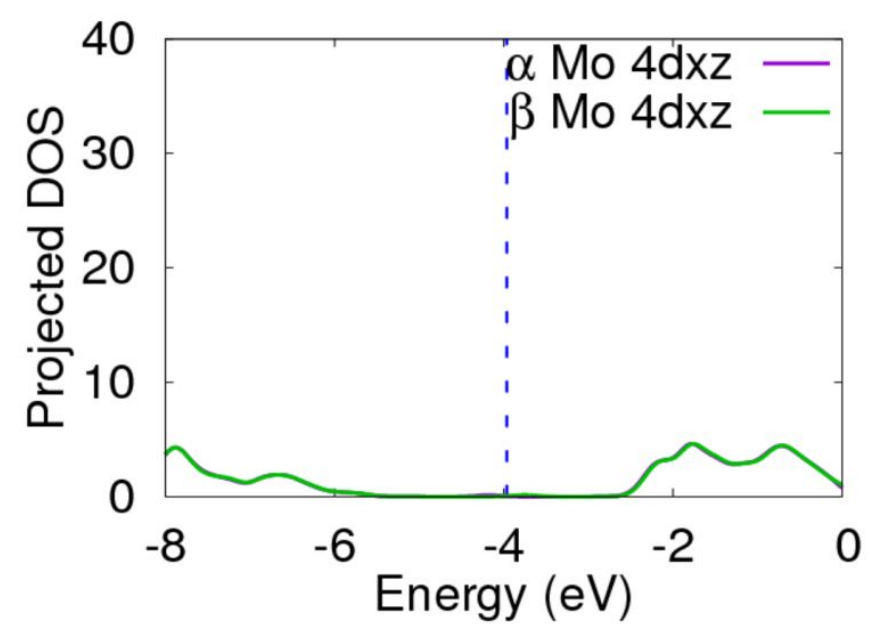

Figure S7. Projected spin-polarized density of states (PDOS) for the given orbital.

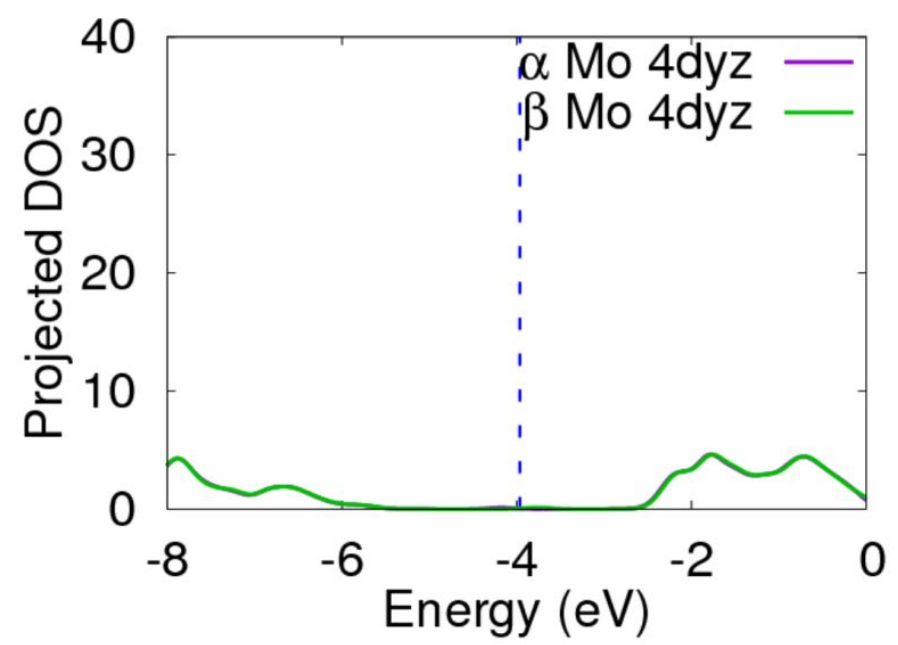

Figure S8. Projected spin-polarized density of states (PDOS) for the given orbital. 


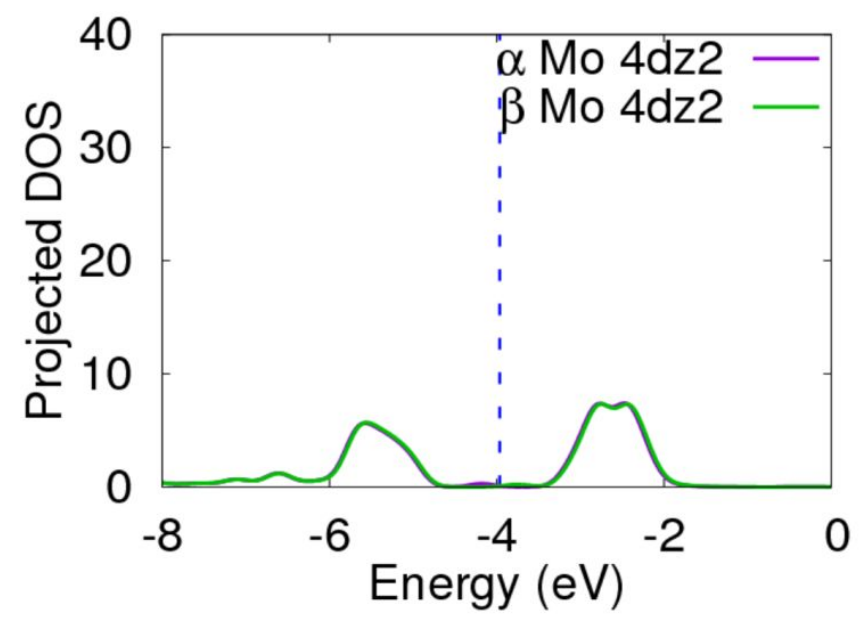

Figure S9. Projected spin-polarized density of states (PDOS) for the given orbital.

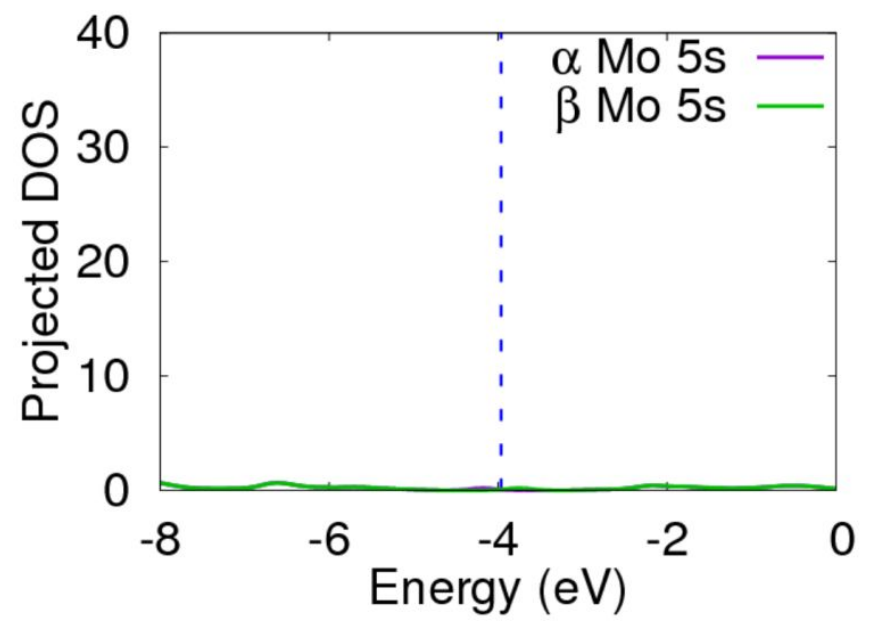

Figure S10. Projected spin-polarized density of states (PDOS) for the given orbital.

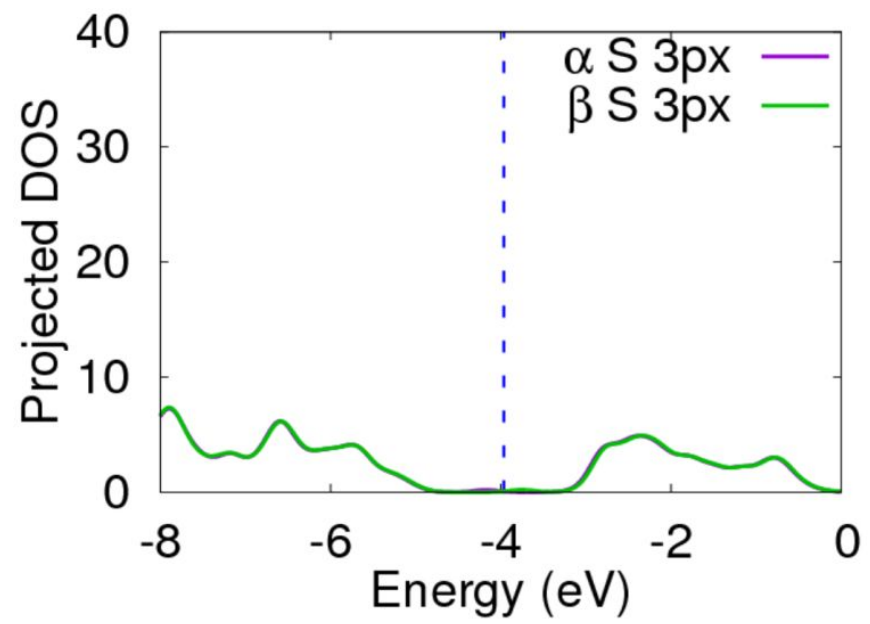

Figure S11. Projected spin-polarized density of states (PDOS) for the given orbital. 


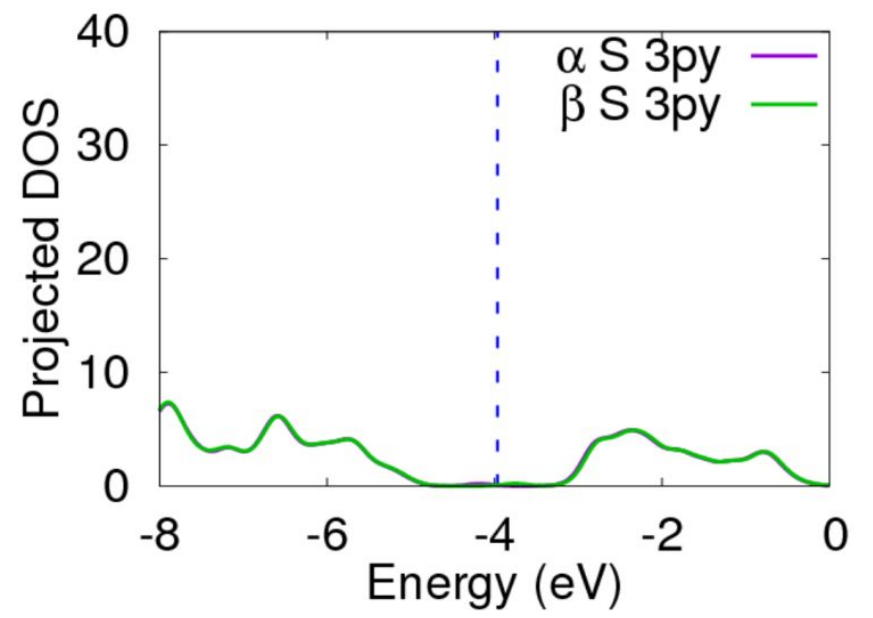

Figure S12. Projected spin-polarized density of states (PDOS) for the given orbital.

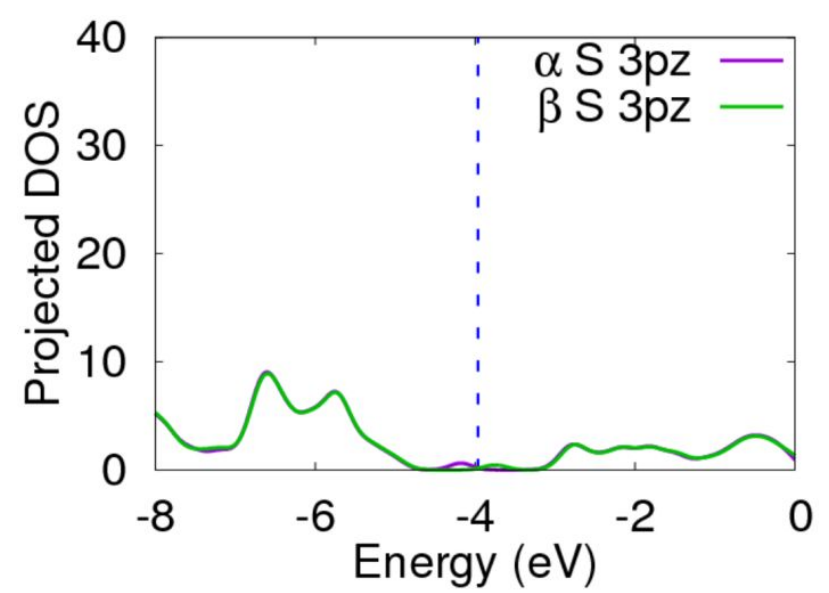

Figure S13. Projected spin-polarized density of states (PDOS) for the given orbital.

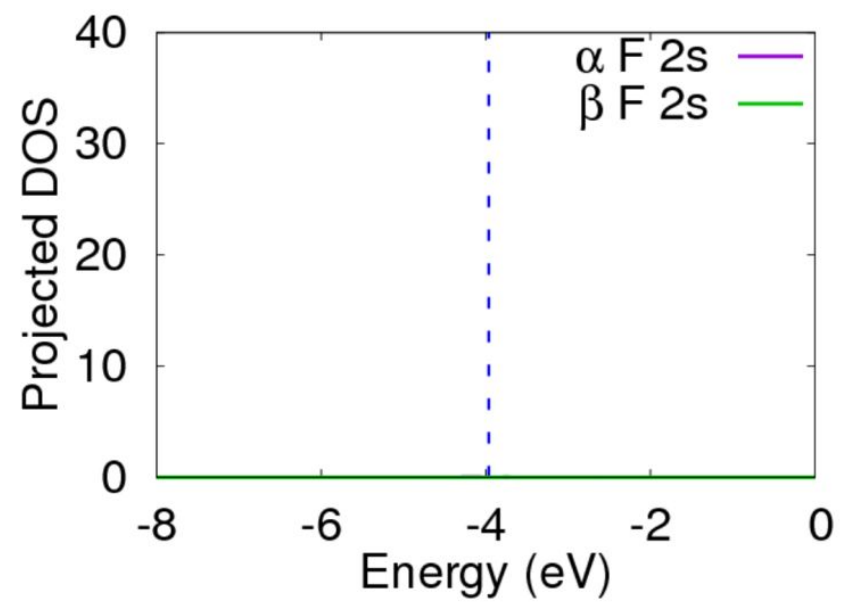

Figure S14. Projected spin-polarized density of states (PDOS) for the given orbital. 


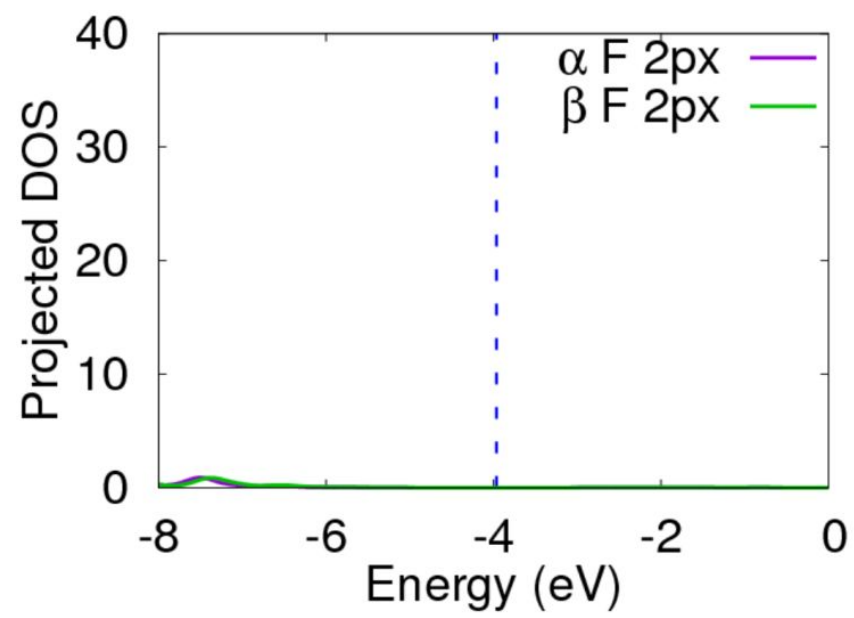

Figure S15. Projected spin-polarized density of states (PDOS) for the given orbital.

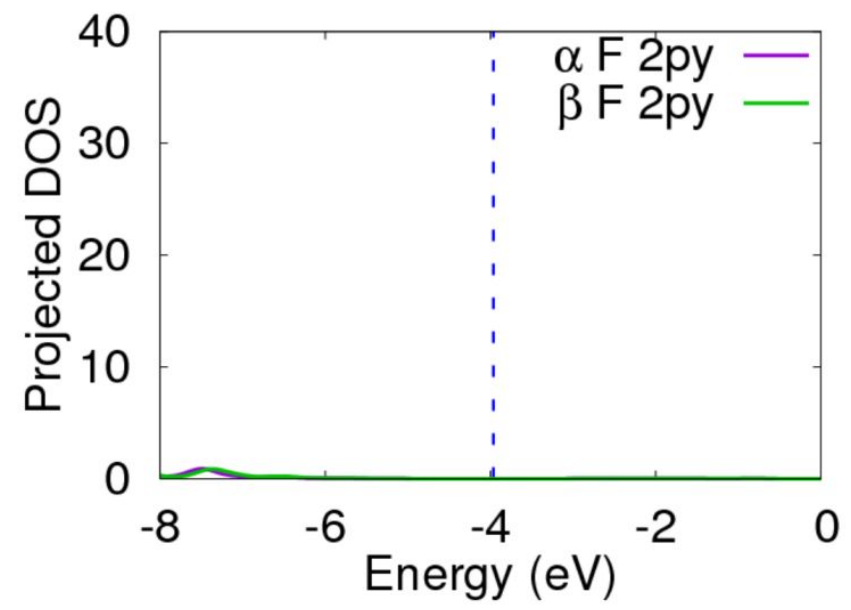

Figure S16. Projected spin-polarized density of states (PDOS) for the given orbital.

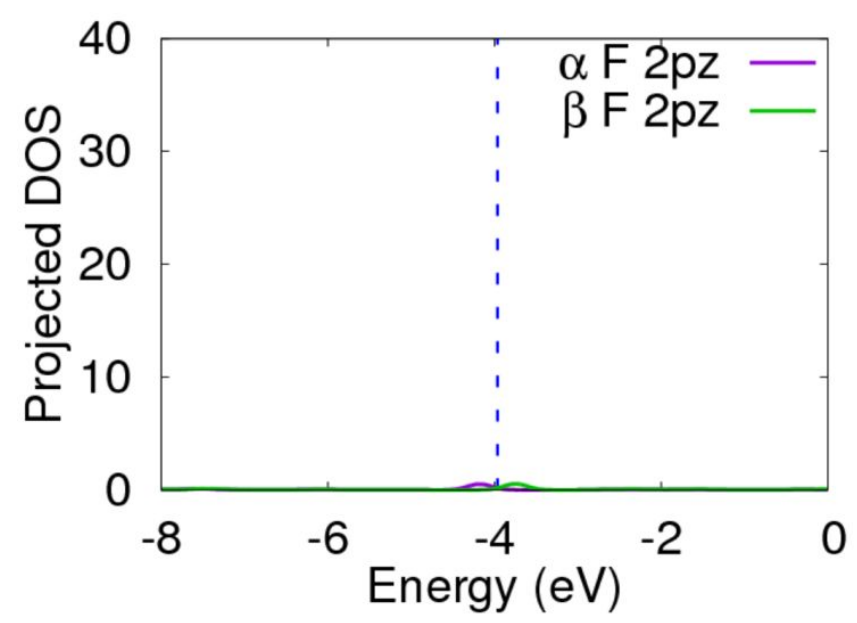

Figure S17. Projected spin-polarized density of states (PDOS) for the given orbital. 


\section{Sulfur Defects}
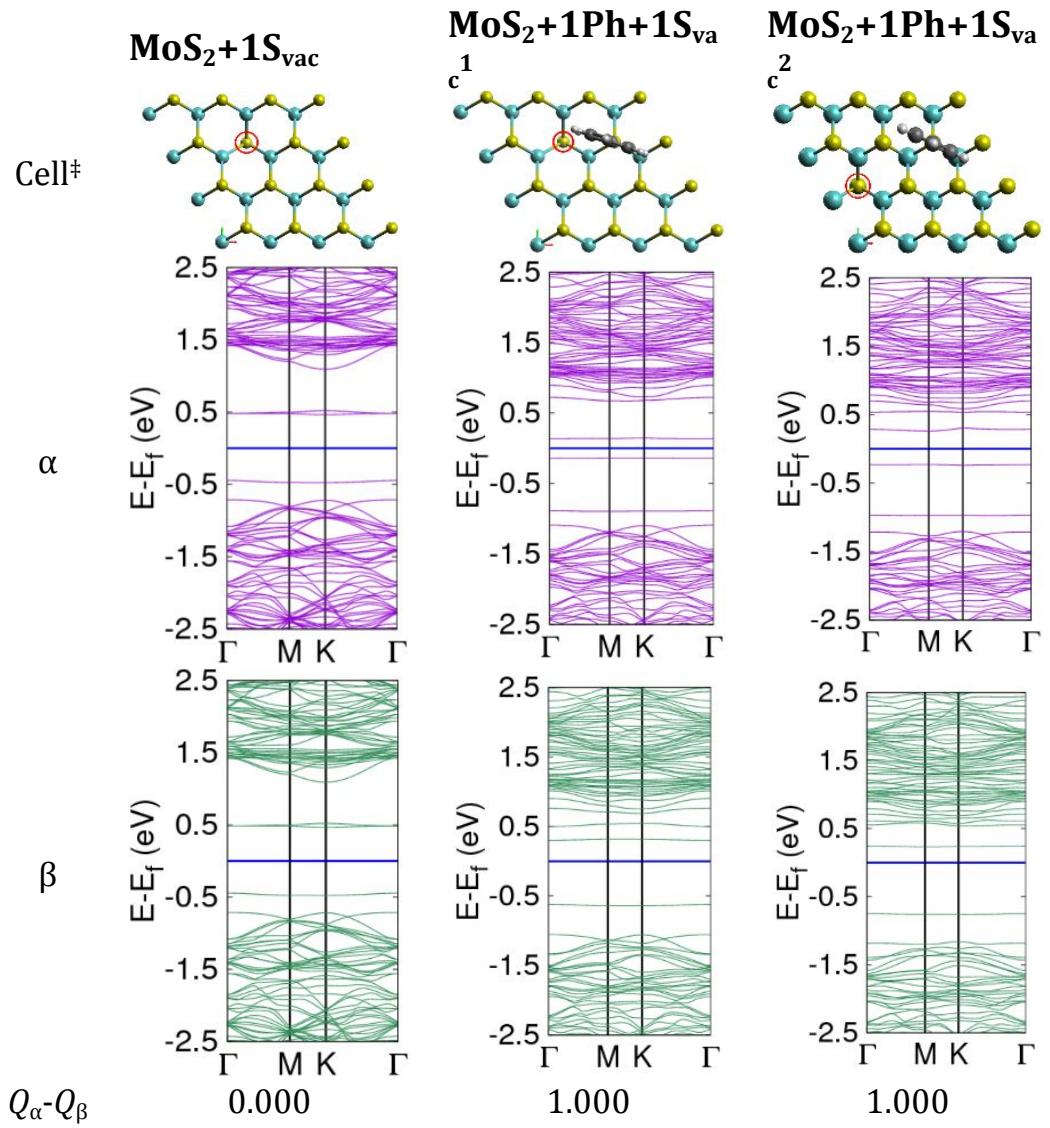

Figure S18. Optimized geometries and band structures of poly-functionalized $\mathrm{MoS}_{2}$ with one phenyl group $(1 \mathrm{Ph})$ and one sulfur vacancy $\left(1 \mathrm{~S}_{\mathrm{vac}} \mathrm{x}\right)$, where $\mathrm{x}=$ identifying label. $\neq$ The position of an $\mathrm{S}$ vacancy is indicated with a red circle. 

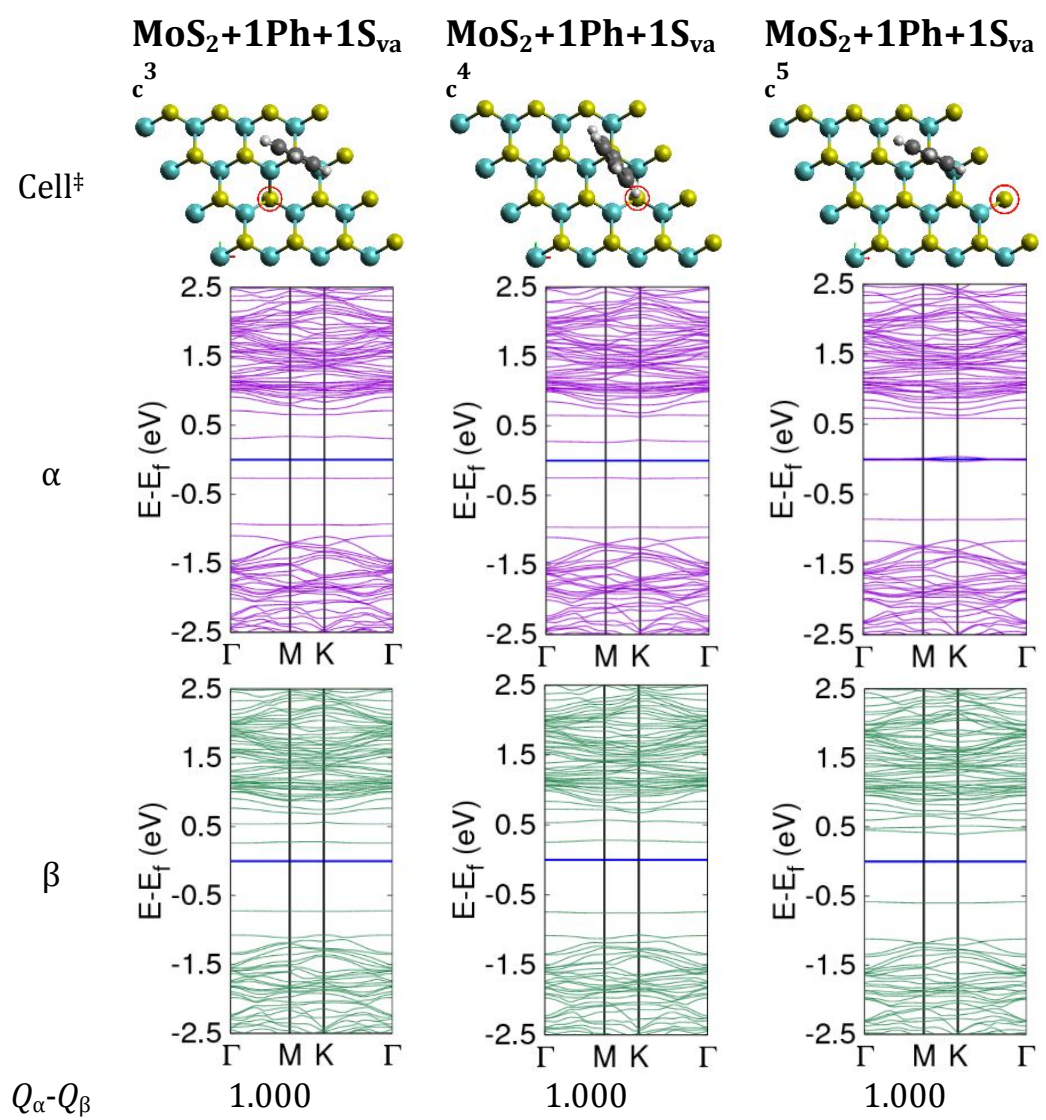

Figure S19. Optimized geometries and band structures of poly-functionalized $\mathrm{MoS}_{2}$ with one phenyl group (1Ph) and one sulfur vacancy $\left(1 \mathrm{~S}_{\text {vac }}{ }^{\mathrm{X}}\right)$, where $\mathrm{x}=$ identifying label. *The position of an $\mathrm{S}$ vacancy is indicated with a red circle. 
Enlarged Band Structures

$\mathrm{MoS}_{2}$
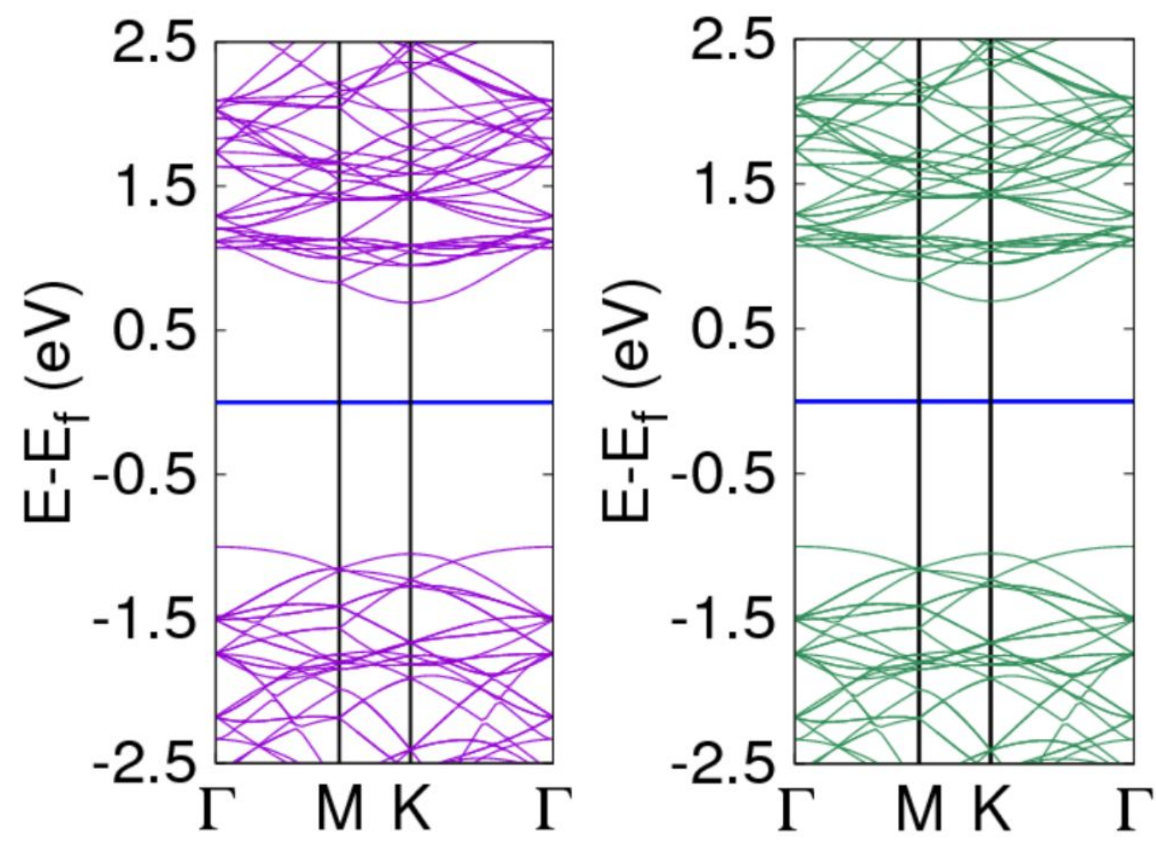

Figure S20. $\alpha$ and $\beta$ band structures.

$\mathrm{MoS}_{2}+\mathrm{F}$
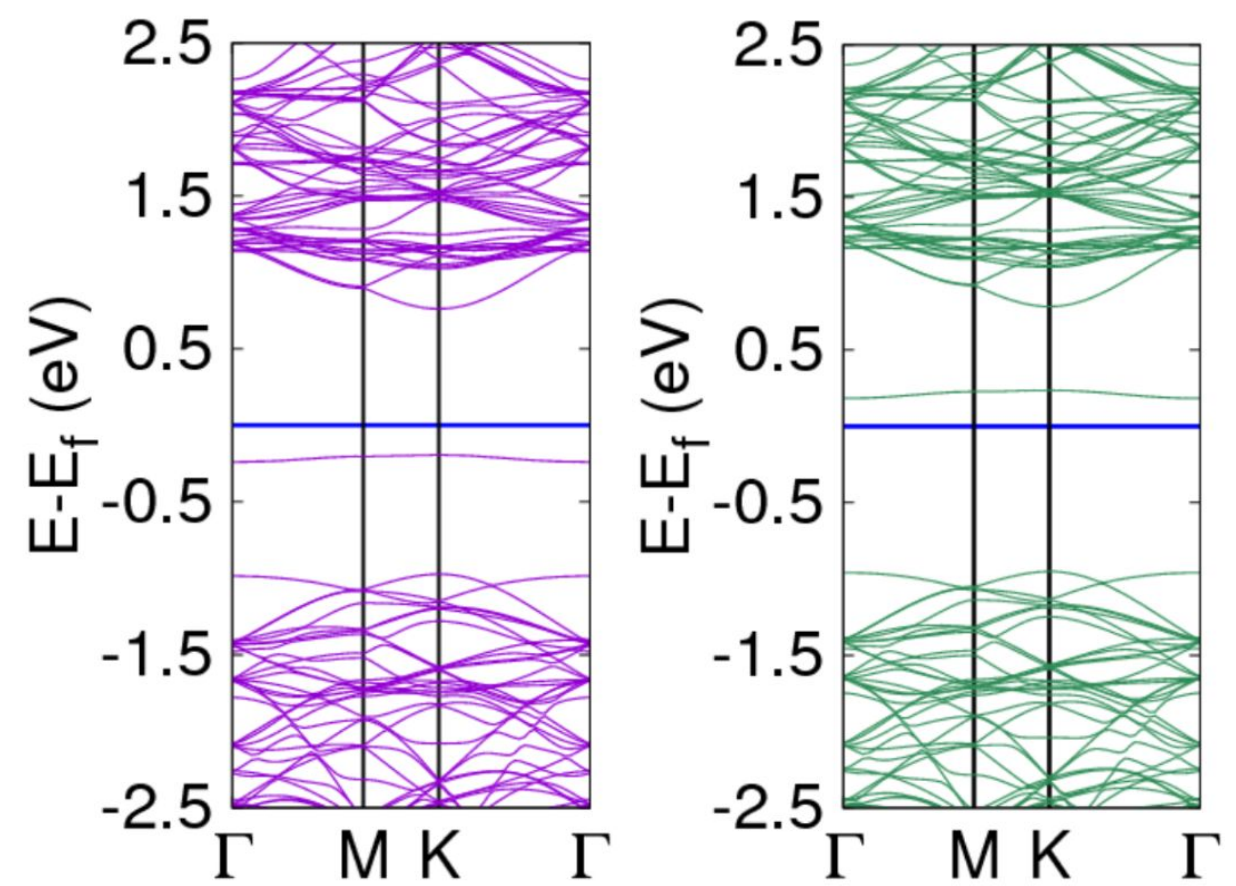

Figure S21. $\alpha$ and $\beta$ band structures. 
$\mathrm{MoS}_{2}+\mathrm{H}$
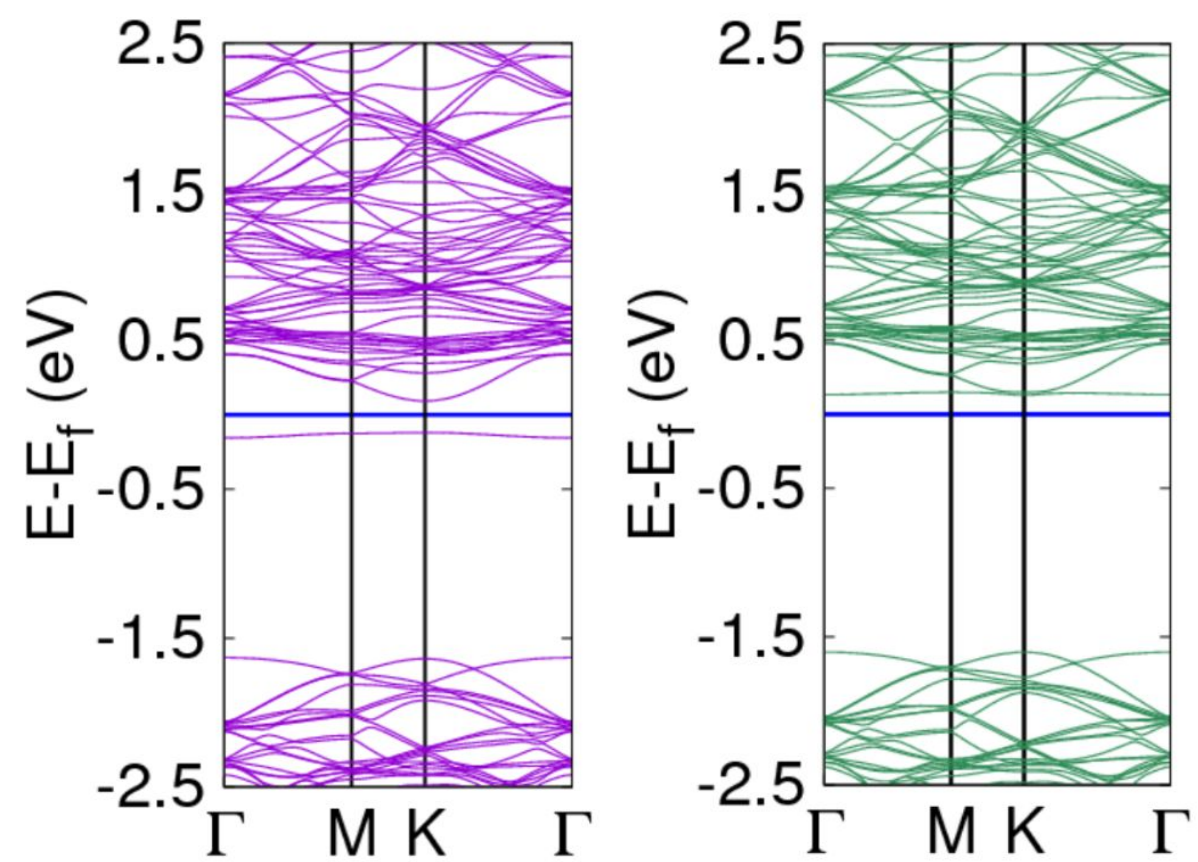

Figure S22. $\alpha$ and $\beta$ band structures.

$\mathrm{MoS}_{2}+\mathrm{Me}$
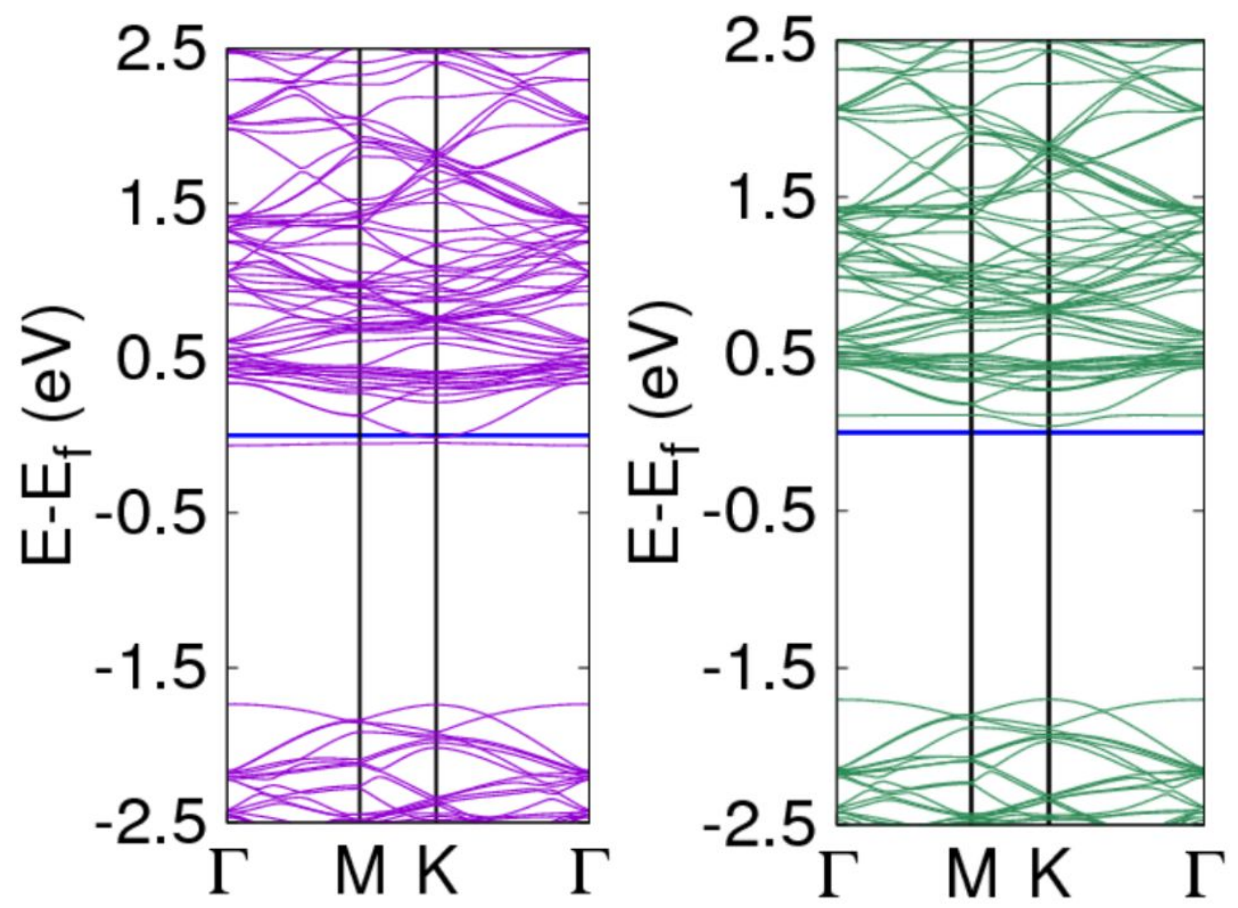

Figure S23. $\alpha$ and $\beta$ band structures.

$\mathrm{MoS}_{2}+\mathrm{Cyc}$ 

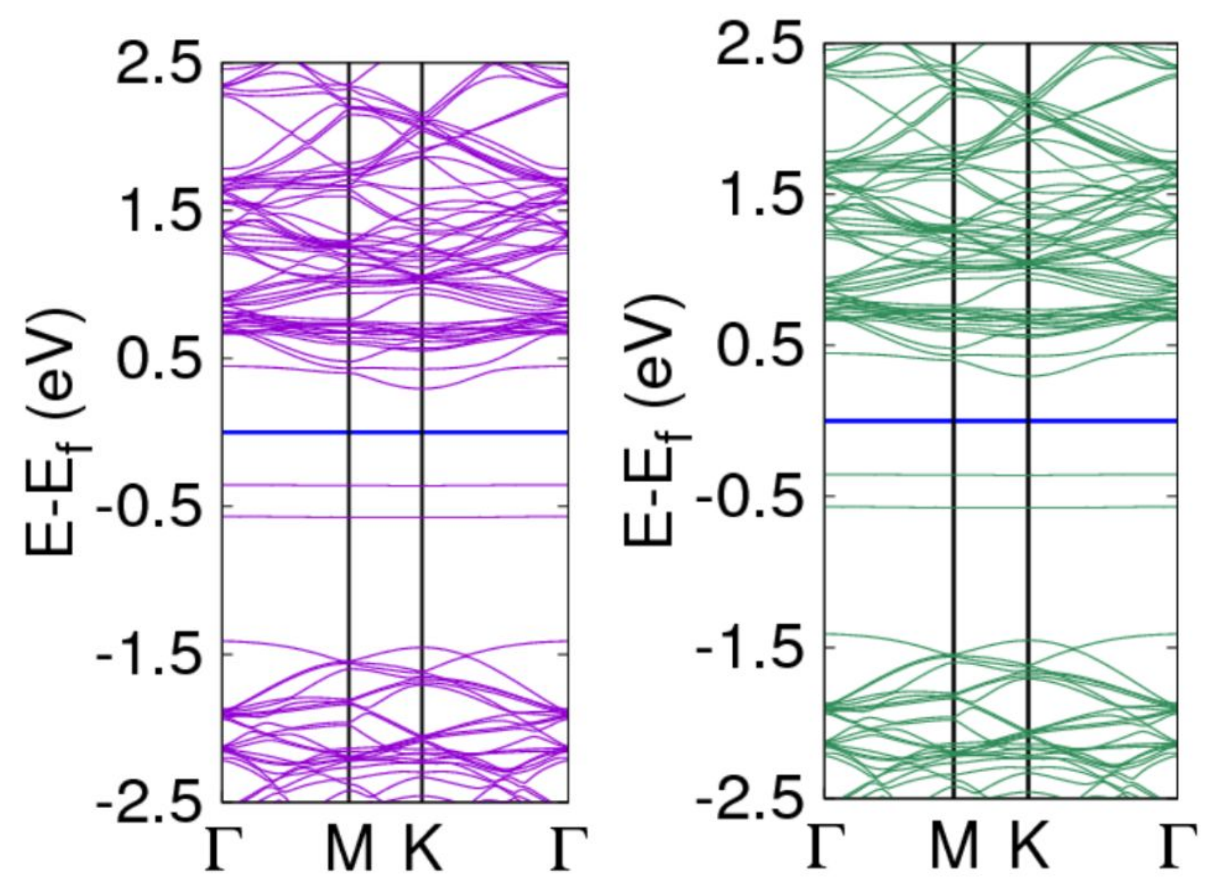

Figure S24. $\alpha$ and $\beta$ band structures.
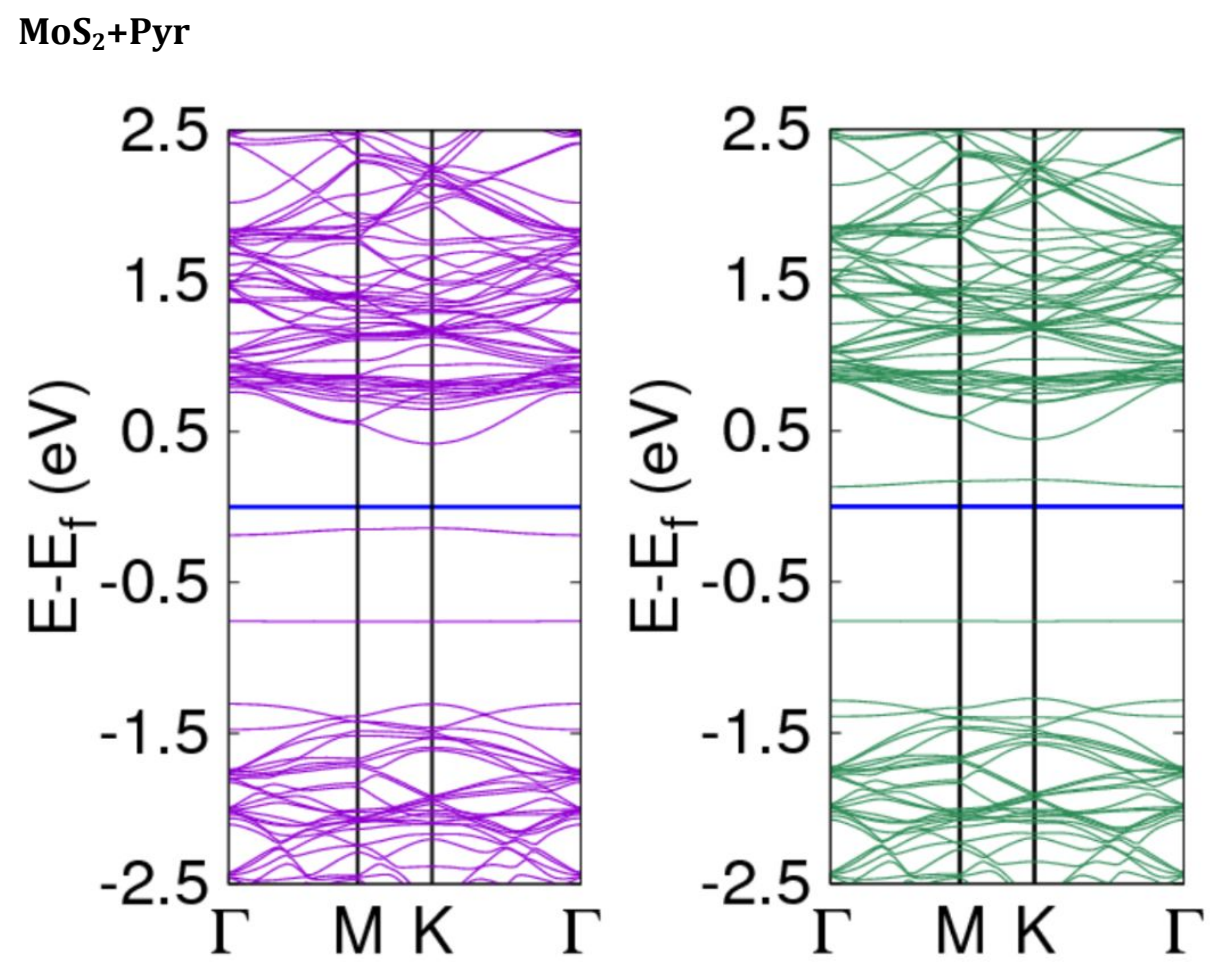

Figure S25. $\alpha$ and $\beta$ band structures. 
$\mathrm{MoS}_{2}+$ Fur
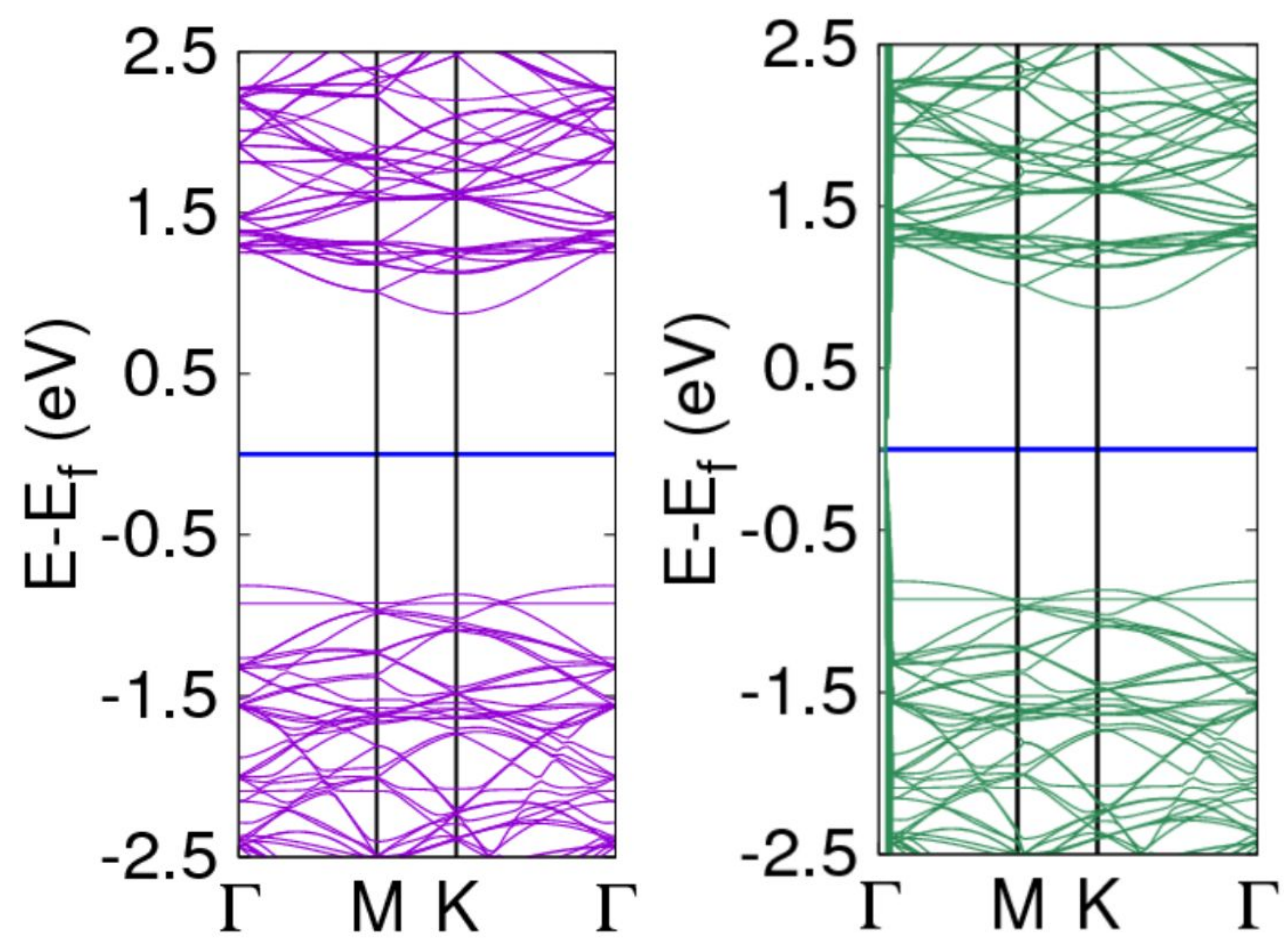

Figure S26 $\alpha$ and $\beta$ band structures.

$\mathrm{MoS}_{2}+\mathrm{Th}$
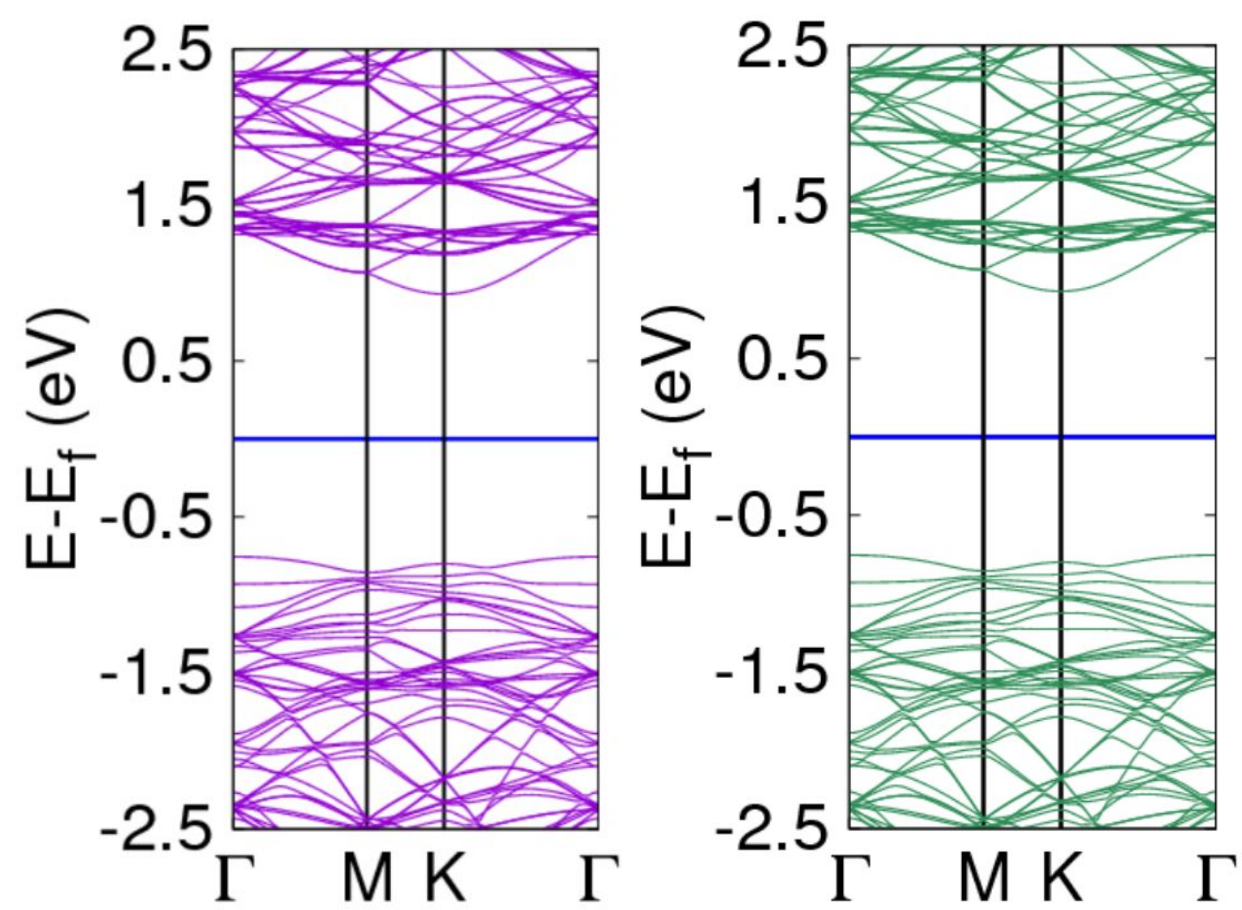

Figure S27. $\alpha$ and $\beta$ band structures.

$\mathrm{MoS}_{2}+\mathrm{Py}$ 

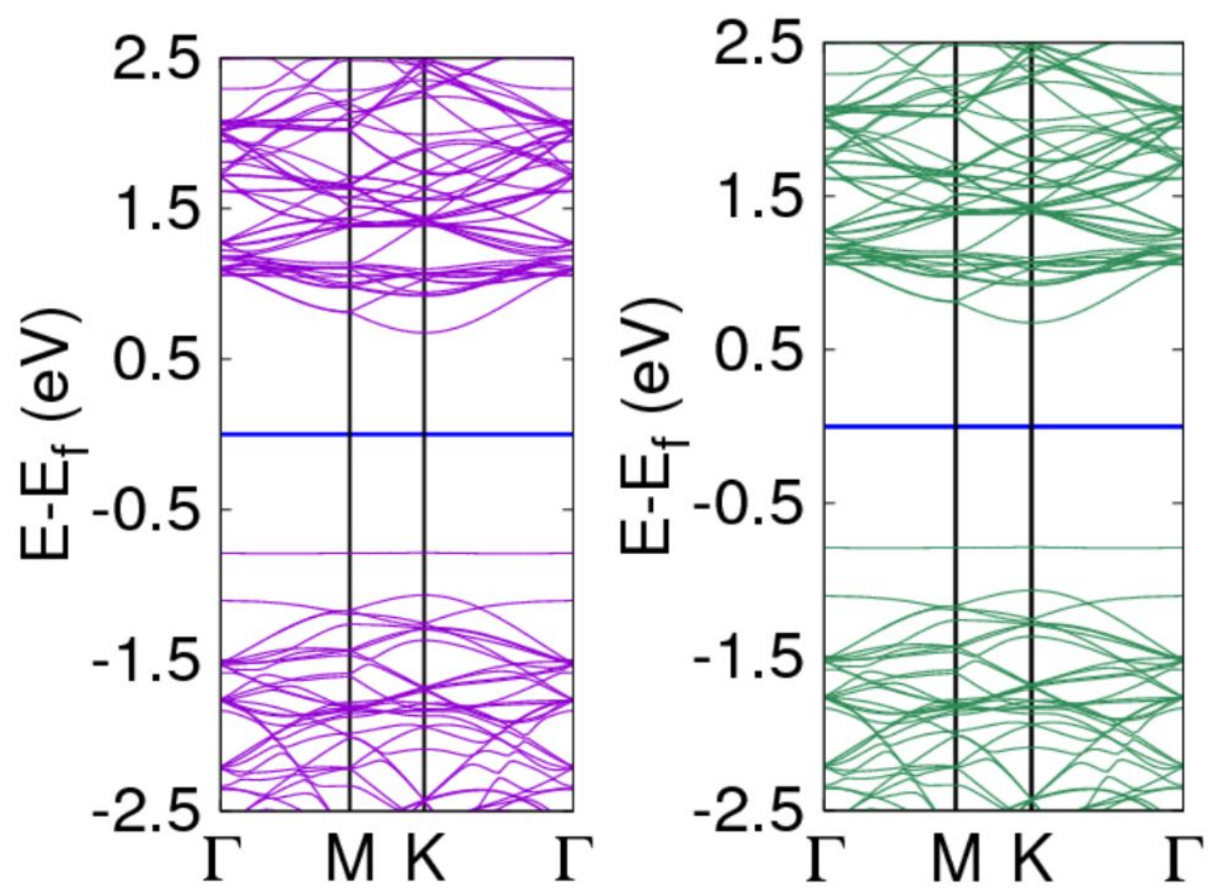

Figure S28. $\alpha$ and $\beta$ band structures.

$\mathrm{MoS}_{2}+\mathrm{Ph}$
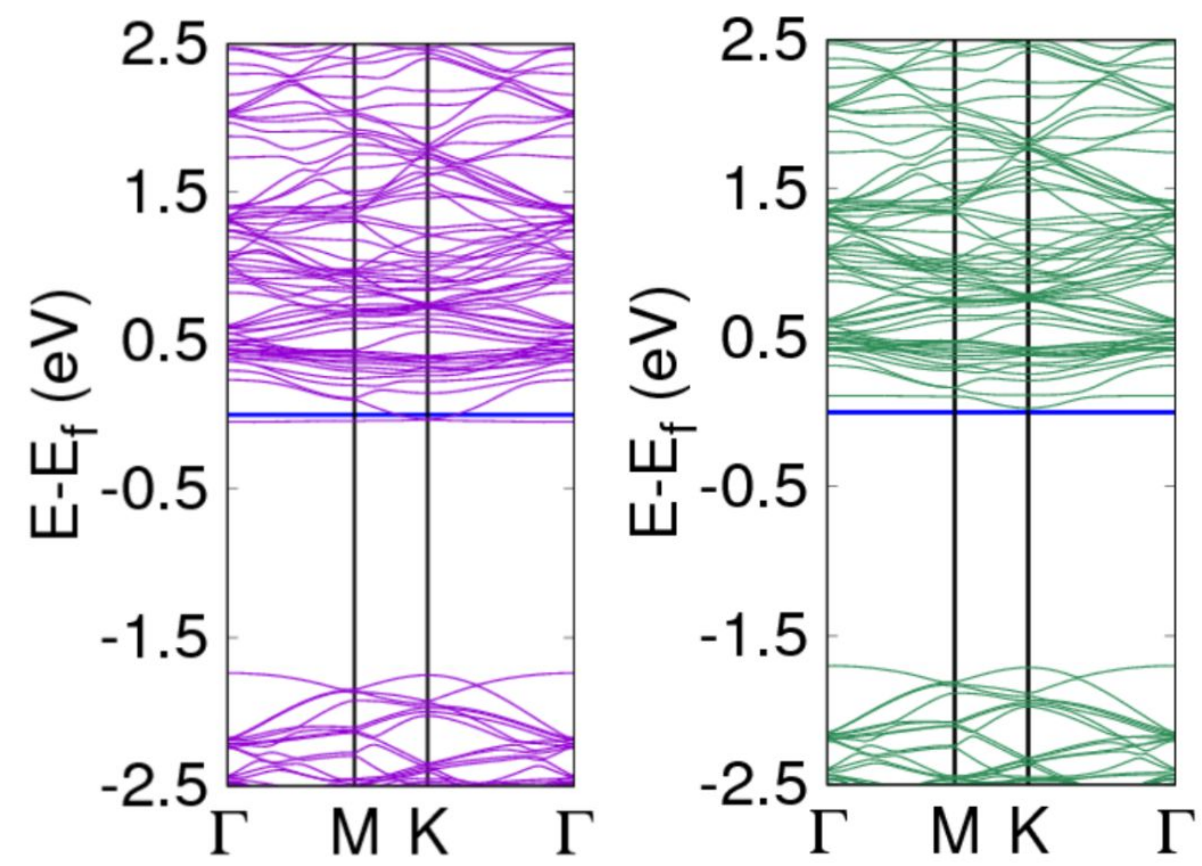

Figure S29. $\alpha$ and $\beta$ band structures. 

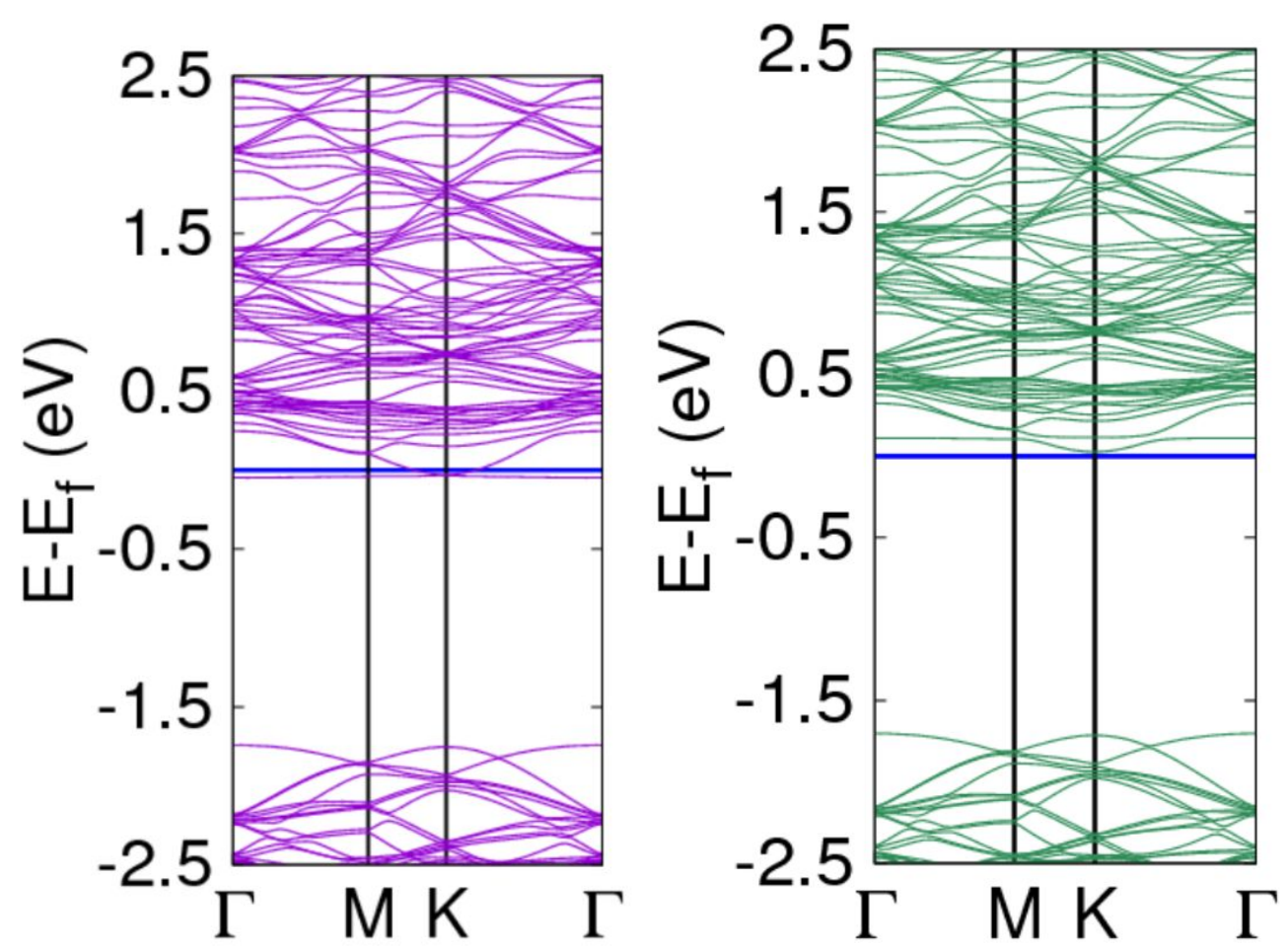

Figure S30. $\alpha$ and $\beta$ band structures.
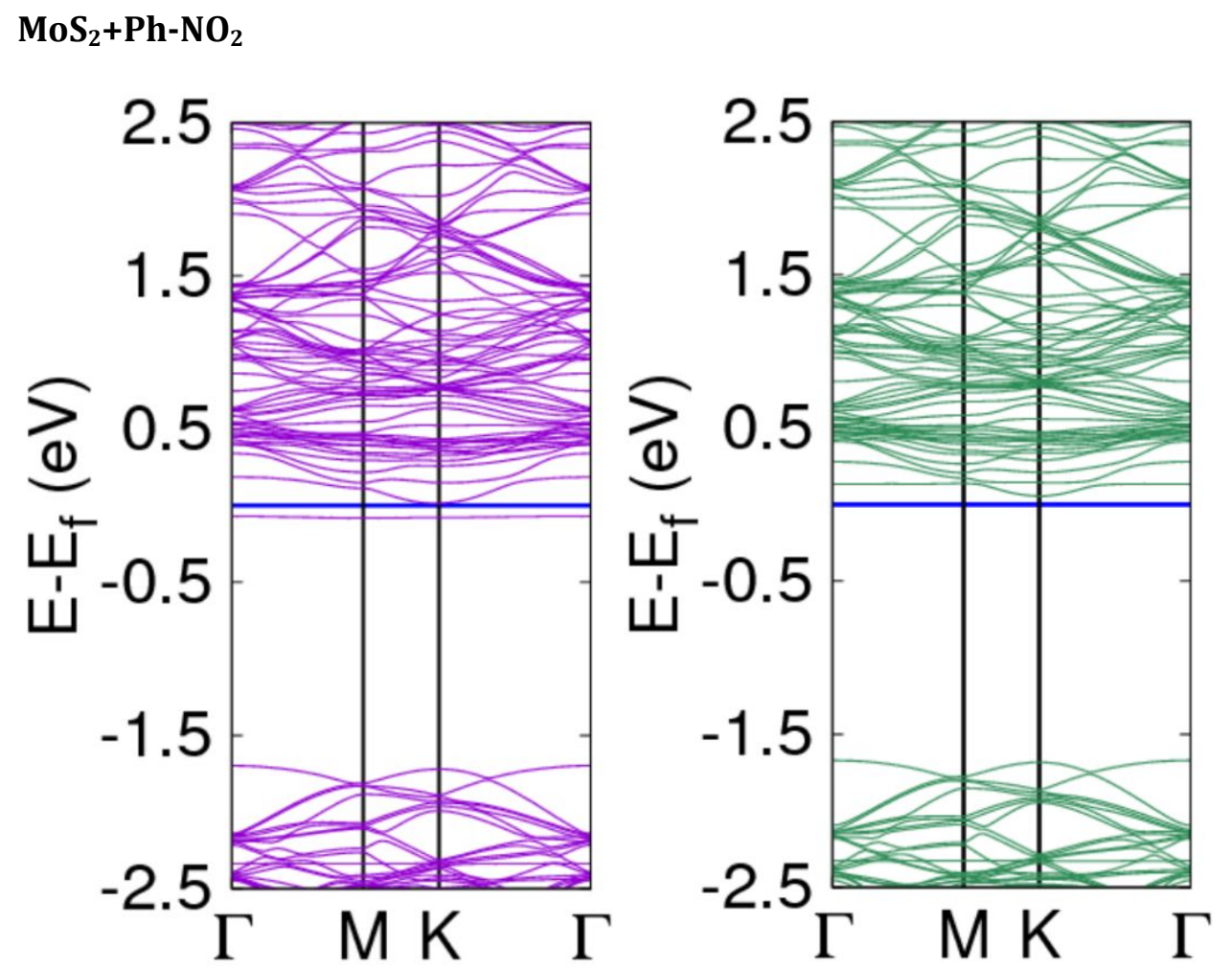

Figure S31. $\alpha$ and $\beta$ band structures. 
$\mathrm{MoS}_{2}+1 \mathrm{e}^{-}$
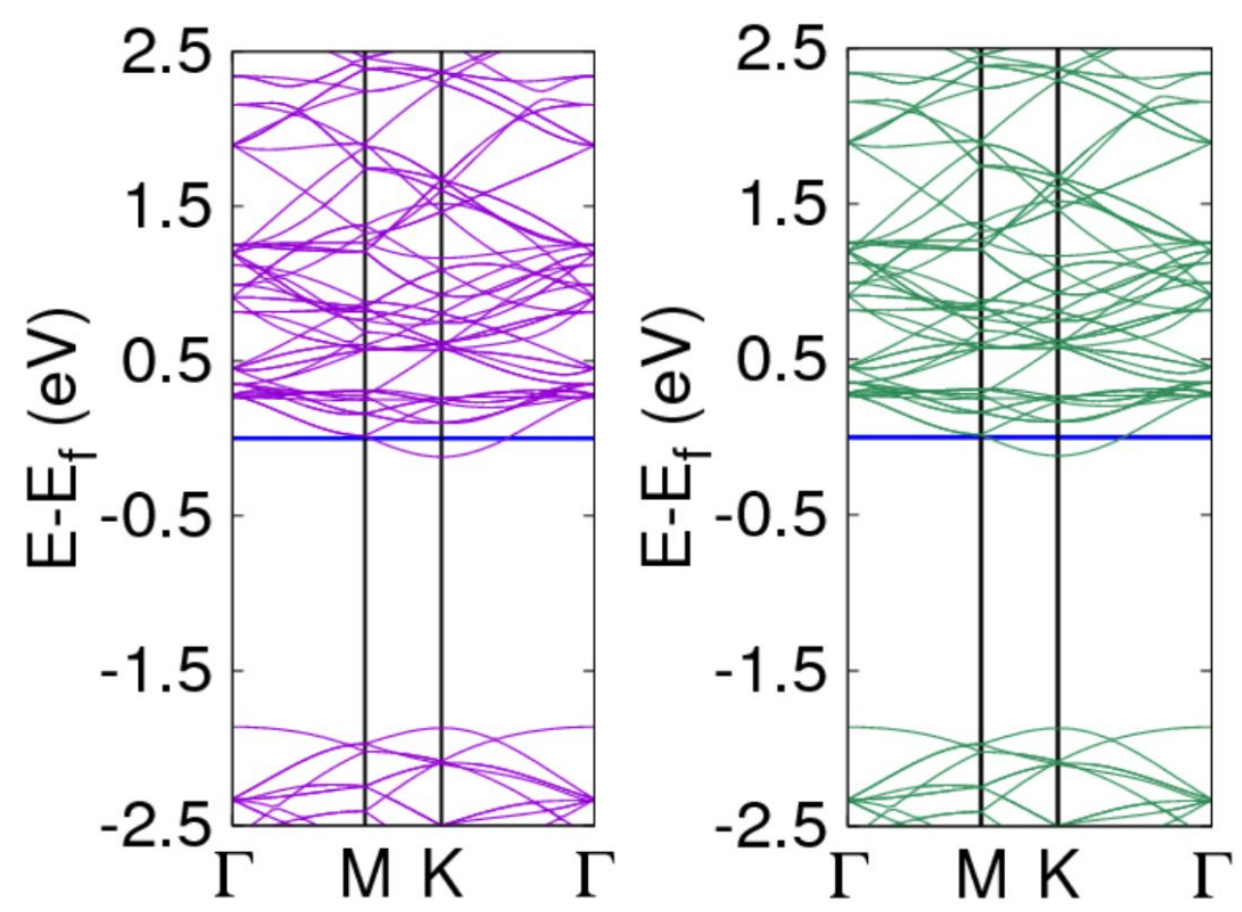

Figure S32. $\alpha$ and $\beta$ band structures.

$\mathrm{MoS}_{2}+2 \mathrm{e}^{-}$
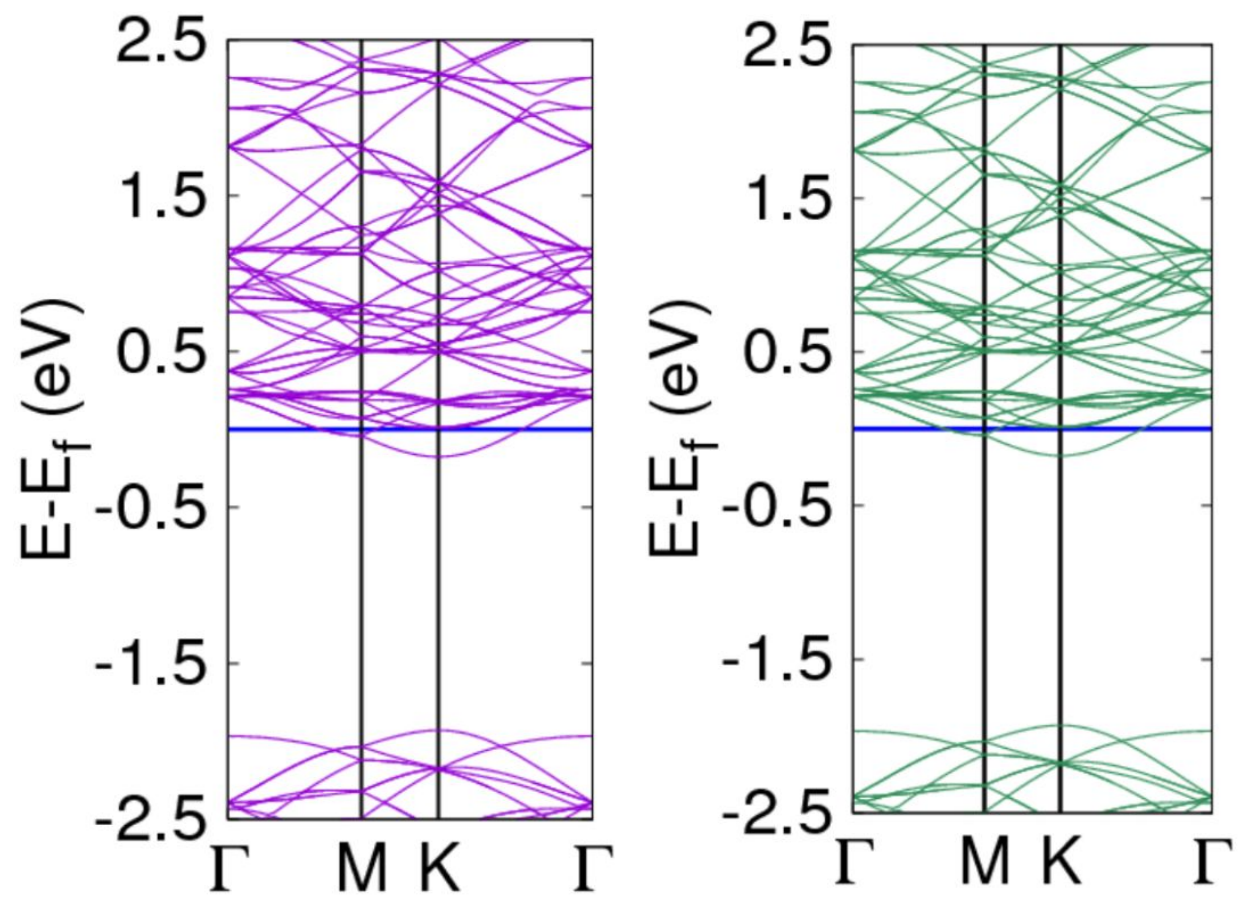

Figure S33. $\alpha$ and $\beta$ band structures.

$\operatorname{MoS}_{2}+1 h^{+}$ 

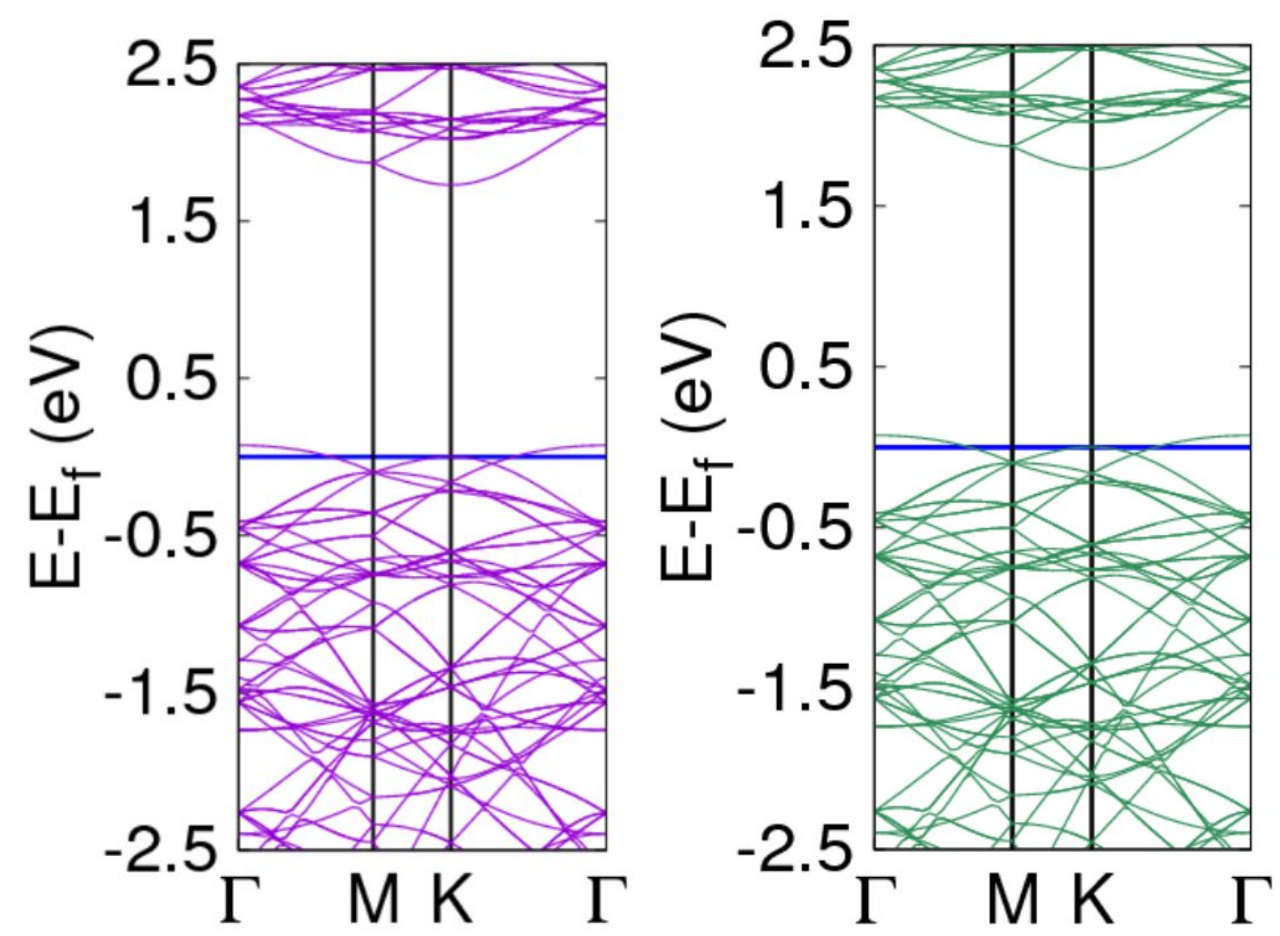

Figure S34. $\alpha$ and $\beta$ band structures.

$\operatorname{MoS}_{2}+2 h^{+}$
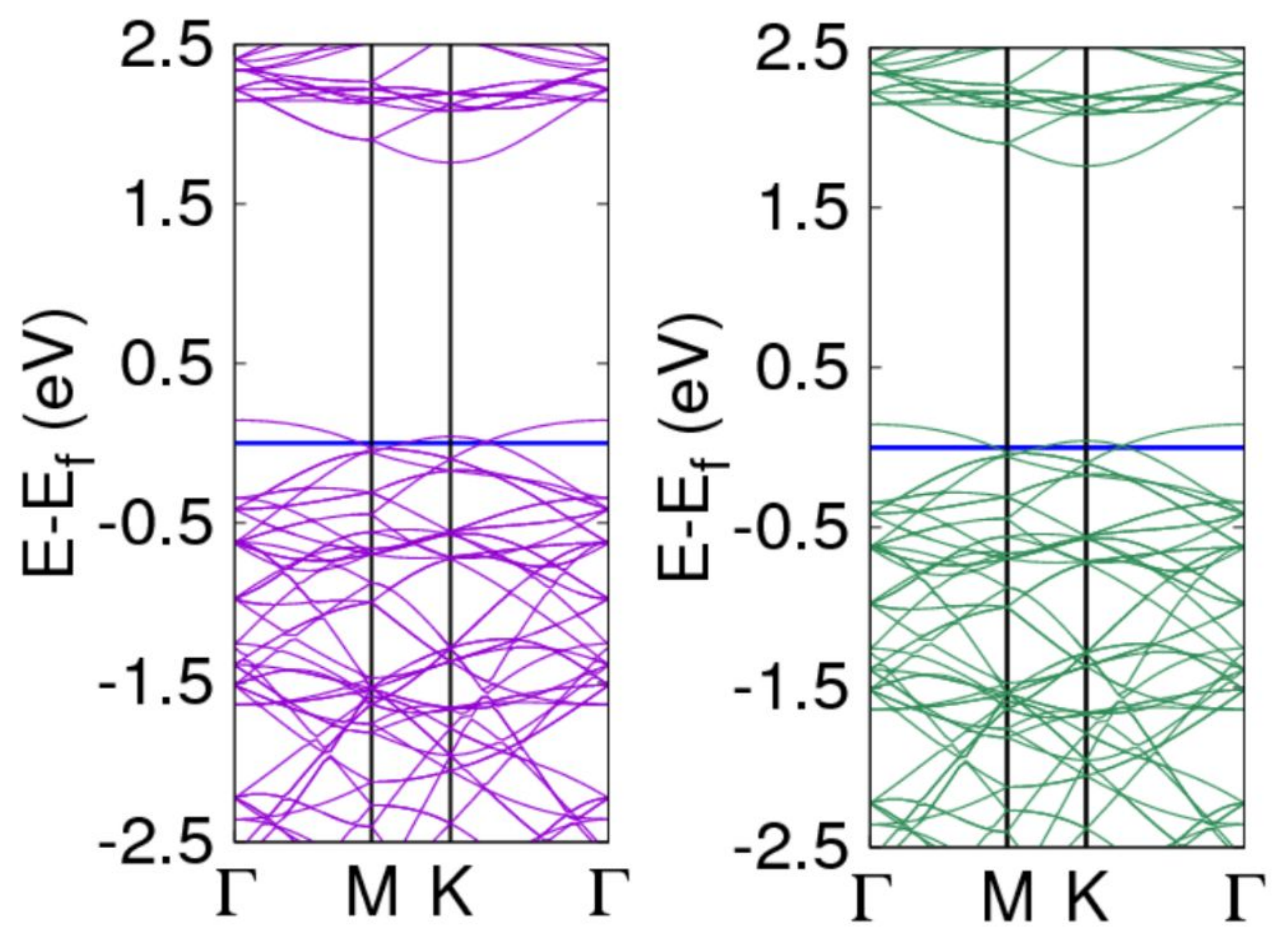

Figure S35. $\alpha$ and $\beta$ band structures.

$\mathrm{MoS}_{2}+\mathrm{Ph}+1 \mathrm{e}^{-}$ 

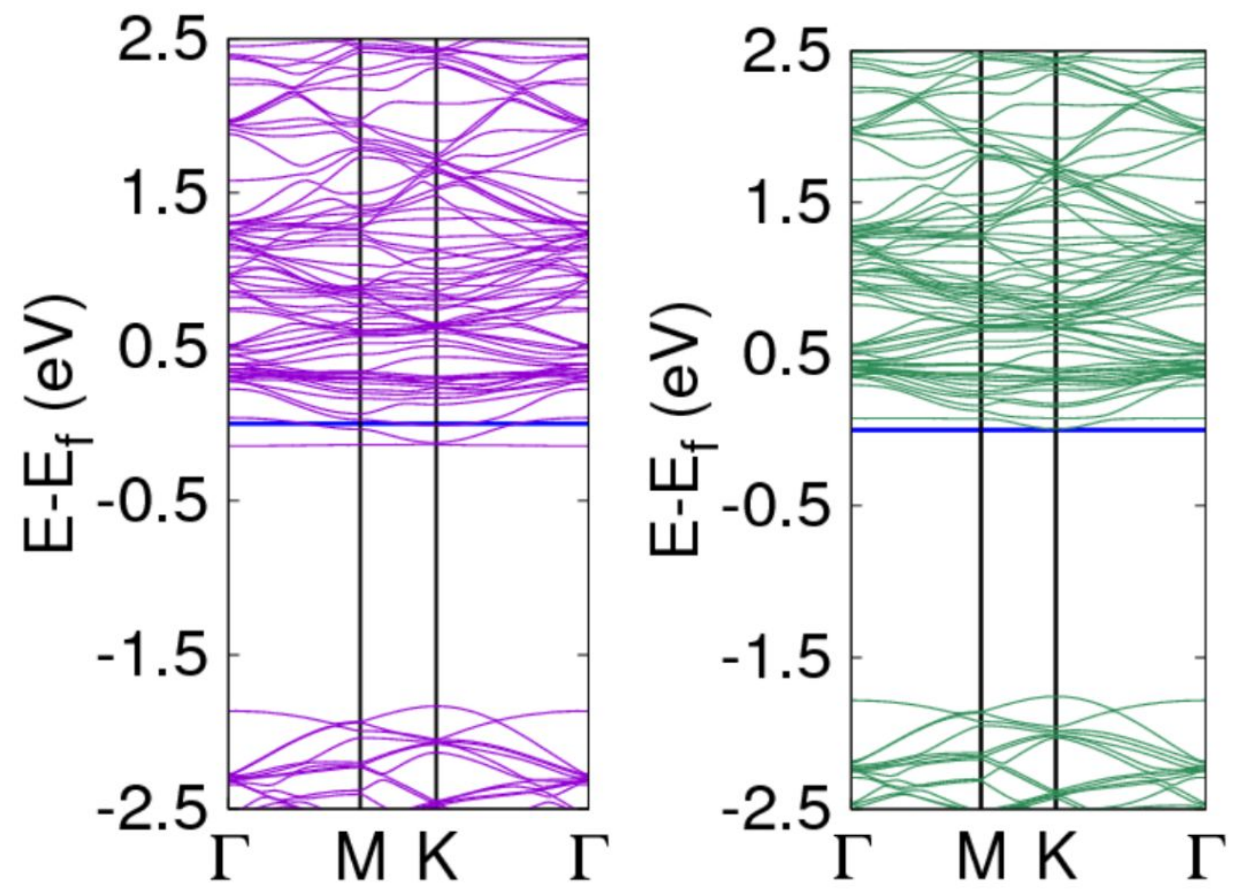

Figure S36. $\alpha$ and $\beta$ band structures.

$\mathrm{MoS}_{2}+\mathrm{Ph}+2 \mathrm{e}^{-}$
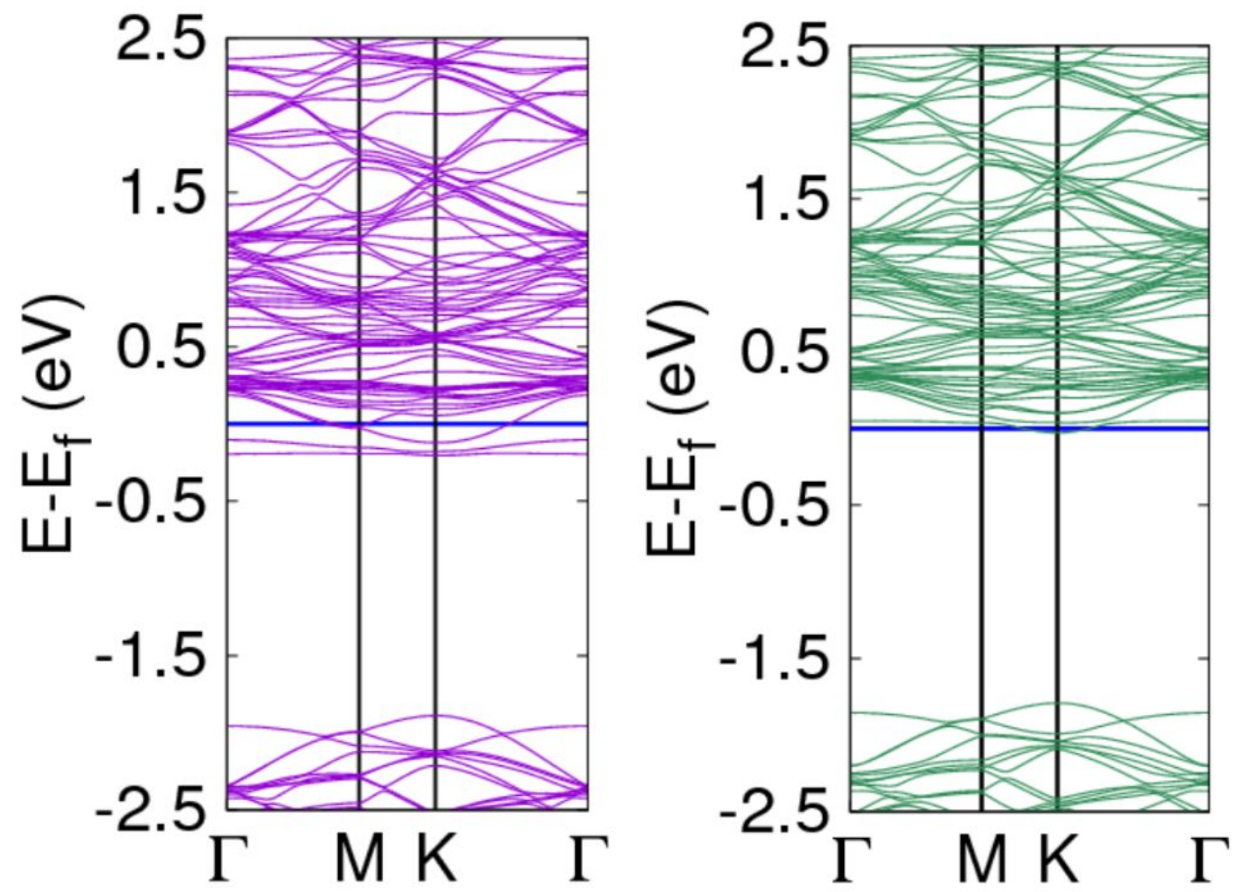

Figure S37. $\alpha$ and $\beta$ band structures.

$\mathrm{MoS}_{2}+\mathrm{Ph}+1 \mathrm{~h}^{+}$ 

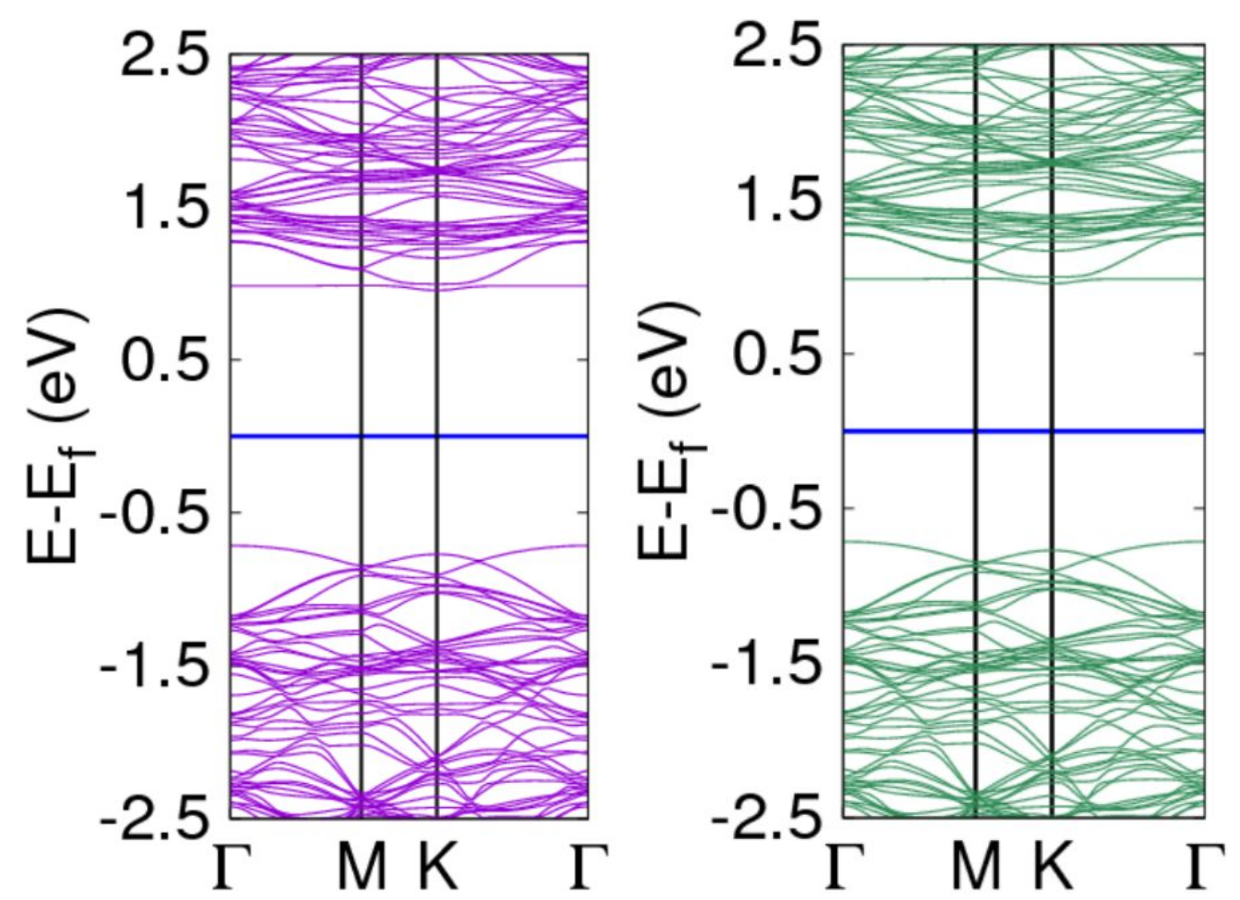

Figure S38. $\alpha$ and $\beta$ band structures.
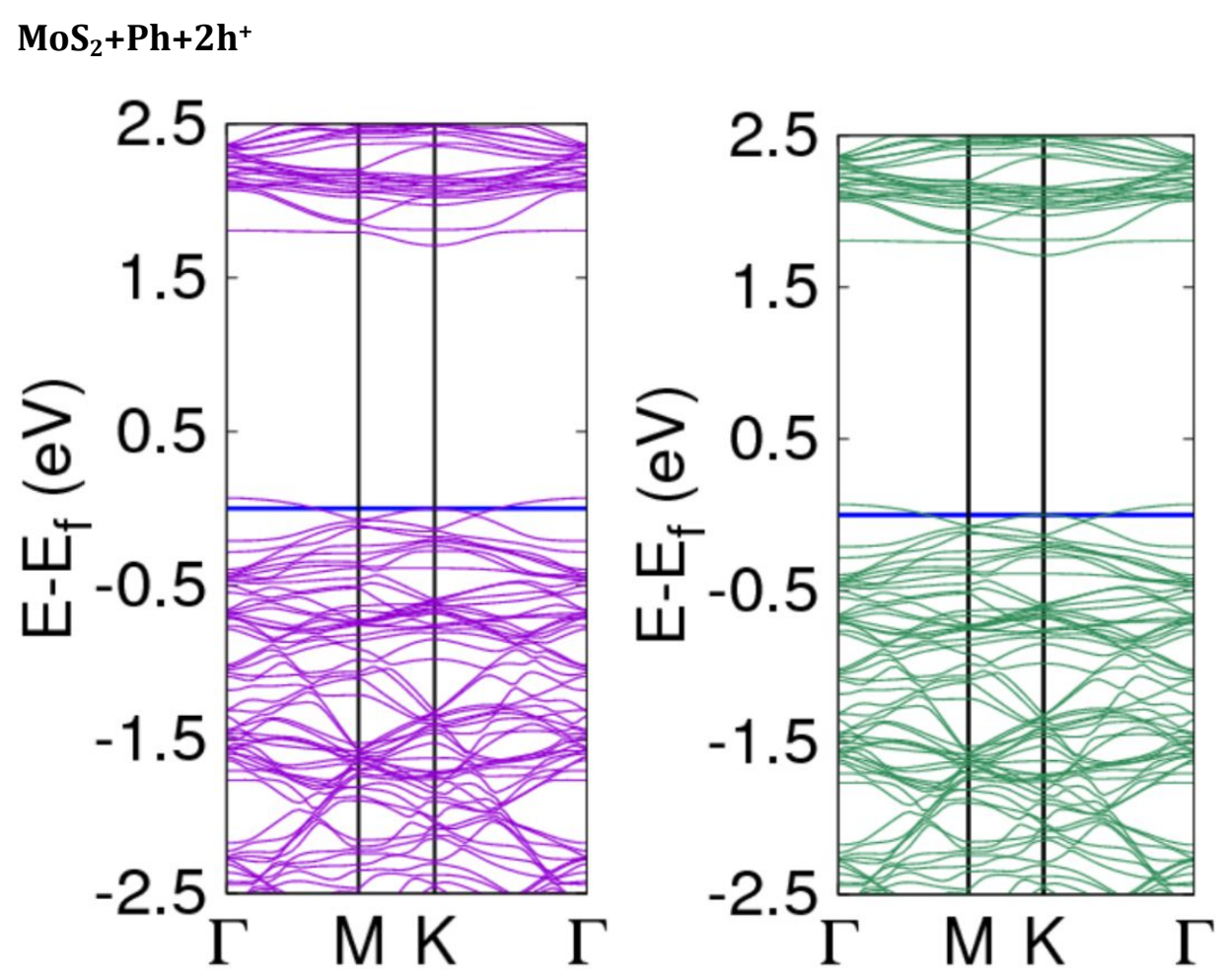

Figure S39. $\alpha$ and $\beta$ band structures. 


\section{References}

(1) Li, Q.; Xu, L.; Luo, K.-W.; Li, X.-F.; Huang, W.-Q.; Wang, L.-L.; Yu, Y.-B. Electric-Field-Induced Widely Tunable Direct and Indirect Band Gaps in HBN/MoS 2 van Der Waals Heterostructures. J. Mater. Chem. C 2017, 5, 4426-4434.

(2) Kośmider, K.; González, J. W.; Fernández-Rossier, J. Large Spin Splitting in the Conduction Band of Transition Metal Dichalcogenide Monolayers. Phys. Rev. B 2013, 88, 245436.

(3) Baik, S. S.; Im, S.; Choi, H. J. Work Function Tuning in Two-Dimensional MoS2 Field-EffectTransistors with Graphene and Titanium Source-Drain Contacts. Sci. Rep. 2017, 7, 45546.

(4) Yue, Q.; Kang, J.; Shao, Z.; Zhang, X.; Chang, S.; Wang, G.; Qin, S.; Li, J. Mechanical and Electronic Properties of Monolayer MoS2 under Elastic Strain. Phys. Lett. A 2012, 376, 1166-1170.

(5) Sung, H.-J.; Choe, D.-H.; Chang, K. J. The Effects of Surface Polarity and Dangling Bonds on the Electronic Properties of Monolayer and Bilayer MoS 2 on $\alpha$-Quartz. New J. Phys. 2014, 16, 113055.

(6) Kan, M.; Wang, J. Y.; Li, X. W.; Zhang, S. H.; Li, Y. W.; Kawazoe, Y.; Sun, Q.; Jena, P. Structures and Phase Transition of a MoS 2 Monolayer. J. Phys. Chem. C 2014, 118, 1515-1522.

(7) Tongay, S.; Suh, J.; Ataca, C.; Fan, W.; Luce, A.; Kang, J. S.; Liu, J.; Ko, C.; Raghunathanan, R.; Zhou, J.; et al. Defects Activated Photoluminescence in Two-Dimensional Semiconductors: Interplay between Bound, Charged and Free Excitons. Sci. Rep. 2013, 3, 2657.

(8) Kumar, A.; Ahluwalia, P. K. A First Principle Comparative Study of Electronic and Optical Properties of $1 \mathrm{H}-\mathrm{MoS} 2$ and $2 \mathrm{H}-\mathrm{MoS2}$. Mater. Chem. Phys. 2012, 135, 755-761.

(9) Li, X.; Wu, S.; Zhou, S.; Zhu, Z. Structural and Electronic Properties of Germanene/MoS2 Monolayer and Silicene/MoS2 Monolayer Superlattices. Nanoscale Res. Lett. 2014, 9, 110.

(10) Kam, K. K.; Parkinson, B. A. Detailed Photocurrent Spectroscopy of the Semiconducting Group VIB Transition Metal Dichalcogenides. J. Phys. Chem. 1982, 86, 463-467.

(11) Mak, K. F.; Lee, C.; Hone, J.; Shan, J.; Heinz, T. F. Atomically Thin MoS 2 : A New Direct-Gap Semiconductor. Phys. Rev. Lett. 2010, 105, 136805. 